\title{
Microscopic simulation of methanol and formaldehyde ice formation in cold dense cores
}

\author{
H. M. Cuppen ${ }^{1}$, E. F. van Dishoeck ${ }^{1,2}$, E. Herbst ${ }^{3}$, and A. G. G. M. Tielens ${ }^{1}$ \\ 1 Leiden Observatory, Leiden University, PO Box 9513, 2300 RA Leiden, The Netherlands \\ e-mail: cuppen@strw.leidenuniv.nl \\ 2 Max-Planck-Institut für Extraterrestrische Physik, Giessenbachstrasse 1, 85748 Garching, Germany \\ 3 Departments of Physics, Astronomy, and Chemistry, The Ohio State University, Columbus, OH 43210, USA
}

Received 14 August 2009 / Accepted 15 October 2009

ABSTRACT

\begin{abstract}
Context. Methanol and its precursor formaldehyde are among the most studied organic molecules in the interstellar medium and are abundant in the gaseous and solid phases. We recently developed a model to simulate $\mathrm{CO}$ hydrogenation via $\mathrm{H}$ atoms on interstellar ice surfaces, the most important interstellar route to $\mathrm{H}_{2} \mathrm{CO}$ and $\mathrm{CH}_{3} \mathrm{OH}$, under laboratory conditions.

Aims. We extend this model to simulate the formation of both organic species under interstellar conditions, including freeze-out from the gas and hydrogenation on surfaces. Our aim is to compare calculated abundance ratios with observed values and with the results of prior models.

Methods. Our model utilises the continuous-time, random-walk Monte Carlo method, which - unlike other approaches - is able to simulate microscopic grain-surface chemistry over the long timescales in interstellar space, including the layering of ices during freeze-out.

Results. Simulations under different conditions, including density and temperature, have been performed. We find that $\mathrm{H}_{2} \mathrm{CO}$ and $\mathrm{CH}_{3} \mathrm{OH}$ form efficiently in cold dense cores or the cold outer envelopes of young stellar objects. The grain mantle is found to have a layered structure with $\mathrm{CH}_{3} \mathrm{OH}$ on top. The species $\mathrm{CO}$ and $\mathrm{H}_{2} \mathrm{CO}$ are found to exist predominantly in the lower layers of ice mantles where they are not available for hydrogenation at late times. This finding is in contrast with previous gas-grain models, which do not take into account the layering of the ice. Some of our results can be reproduced by a simple quasi-steady-state analytical model that focuses on the outer layer.

Conclusions. Observational solid $\mathrm{H}_{2} \mathrm{CO} / \mathrm{CH}_{3} \mathrm{OH}$ and $\mathrm{CO} / \mathrm{CH}_{3} \mathrm{OH}$ abundance ratios in the outer envelopes of an assortment of young stellar objects agree reasonably well with our model results, which also suggest that the large range in $\mathrm{CH}_{3} \mathrm{OH} / \mathrm{H}_{2} \mathrm{O}$ observed abundance ratios is due to variations in the evolutionary stages. Finally, we conclude that the limited chemical network used here for surface reactions apparently does not alter the overall conclusions.
\end{abstract}

Key words. astrochemistry - methods: numerical - molecular processes - ISM: molecules - ISM: clouds

\section{Introduction}

Methanol and its precursor formaldehyde are among the most studied organic molecules in the interstellar medium (ISM). Both species have been observed in the gas phase and as constituents of ice mantles. Whereas gas-phase detections of both molecules have been numerous, (e.g., Jørgensen et al. 2005; Maret et al. 2004, 2005; Schöier et al. 2004; van der Tak et al. 2000) and methanol is a well-known constituent of the ice (Allamandola et al. 1992; Dartois et al. 1999; Herbst \& van Dishoeck 2009), there are only a few secure solid-state detections of $\mathrm{H}_{2} \mathrm{CO}$. These detections occur mostly in high-mass young stellar sources such as W33A, GL2136, and GL 989, and often only upper limits are given (Boogert et al. 2008; Gibb et al. 2004). For example, Pontoppidan et al. (2004) found an upper limit for the $\mathrm{H}_{2} \mathrm{CO}$ ice abundance in the outer envelope of the low-mass young stellar source Serpens SMM 4 of 5\% with respect to water ice. $\mathrm{CH}_{3} \mathrm{OH}$ ice has a much higher abundance of $28 \%$ with respect to water in this source, resulting in an $\mathrm{H}_{2} \mathrm{CO} / \mathrm{CH}_{3} \mathrm{OH}$ ice ratio of less than 0.18 . Typically, in sources where both species have been detected, the observed $\mathrm{H}_{2} \mathrm{CO} / \mathrm{CH}_{3} \mathrm{OH}$ ratio is still smaller than unity, with values ranging from 0.09 to 0.5 . Sub-millimetre observations of the gas in seven massive hot-cores show a similar trend: Bisschop et al (2007) found a constant ratio of gas phase $\mathrm{H}_{2} \mathrm{CO} / \mathrm{CH}_{3} \mathrm{OH}$ between 0.13 and 0.28 .

In this paper, we aim to develop a model that explains these observed abundances and abundance ratios and to study the implications for the conditions in regions where they are found. Following Tielens \& Hagen (1982) and Charnley et al. (1992) and supported by numerous laboratory studies on hydrogenation of CO (Fuchs et al. 2009; Hiraoka et al. 2002; Watanabe \& Kouchi 2002), we assume that methanol and formaldehyde are formed from hydrogenation of $\mathrm{CO}$ on grain surfaces. Observations have revealed that $\mathrm{CO}$ is present in three distinct components in interstellar ices: non-polar (pure) $\mathrm{CO}, \mathrm{CO}$ mixed with $\mathrm{CO}_{2}$ and $\mathrm{CO}$ as a trace in polar ice (Chiar et al. 1998; Pontoppidan et al. 2008; Tielens et al. 1991). Here, we exclusively focus on methanol formation during the condensation/formation of the non-polar CO component. This component is thought to be formed when the cloud density increases and the gaseous atomic $\mathrm{H} / \mathrm{CO}$ ratio decreases (Tielens \& Hagen 1982), and thus occurs at a later stage or deeper in the cloud than the water ice formation. This is consistent with the higher observed extinction threshold for $\mathrm{CO}$ ice formation compared with that of $\mathrm{H}_{2} \mathrm{O}$ (Whittet et al. 2001). In the highest density 
regions ( $>$ few $\times 10^{5} \mathrm{~cm}^{-3}$ ), the timescales for collisions of $\mathrm{CO}$ with the grains become so short that most of the gaseous $\mathrm{CO}$ is removed from the gas. This so-called "catastrophic" CO freezeout has been observed directly through infrared ice-mapping observations (Pontoppidan 2006) and indirectly through the lack of gas-phase $\mathrm{CO}$ (and other molecules) from the densest parts of the core, e.g., L1544, B68 (Bergin et al. 2002; Caselli et al. 1999), as well as the accompanying rise in $\mathrm{H}_{2} \mathrm{D}^{+}$and the deuterated molecules. In such high density regions, the bulk of the $\mathrm{CO}$ ice is in the pure form. For this pure CO-ice component, we can thus be assured that $\mathrm{CO}$ is the main reaction partner of accreted hydrogen and hence all the relevant reactions have been studied experimentally. For the other $\mathrm{CO}$ ice environments, competition with other reactions clearly plays an important role, in particular hydrogenation of atomic oxygen to water. We briefly comment on this competition in Sect. 5 but leave the formation of methanol and formaldehyde in these other interstellar ice environments to a future paper.

The formation route of methanol ice by hydrogenation of solid CO studied in the laboratory consists of the following steps:

$\mathrm{CO} \rightarrow \mathrm{HCO} \rightarrow \mathrm{H}_{2} \mathrm{CO} \rightarrow \mathrm{H}_{2} \mathrm{COH} \rightarrow \mathrm{CH}_{3} \mathrm{OH}$,

where the reactions involving $\mathrm{CO}$ and $\mathrm{H}_{2} \mathrm{CO}$ possess small activation energy barriers. The experiments all show that for a range of temperatures and $\mathrm{H}$-fluences (time $\times$ flux) that are comparable with fluences in the ISM, the $\mathrm{H}_{2} \mathrm{CO}$ rate of production is equal to or higher than the formation rate of $\mathrm{CH}_{3} \mathrm{OH}$. This result appears to be in contradiction with the observational evidence. In a recent paper (Fuchs et al. 2009), we showed by means of microscopic Monte Carlo simulations that high $\mathrm{H}$-atom laboratory fluxes and low $\mathrm{H}$-atom interstellar fluxes do not result in the same production rate of $\mathrm{H}_{2} \mathrm{CO}$ and $\mathrm{CH}_{3} \mathrm{OH}$, even if the overall fluences are the same. The difference arises because most of the hydrogen atoms in the high-flux regime form molecular hydrogen whereas in the interstellar regime the hydrogenation reactions dominate (Fuchs et al. 2009). The crossover from $\mathrm{H}_{2} \mathrm{CO}$-rich conditions to $\mathrm{CH}_{3} \mathrm{OH}$-rich conditions occurs therefore at much earlier times than expected from a direct translation of the laboratory environment. Moreover, the simulations presented in the Fuchs et al. (2009) paper are for hydrogenation on pure CO ice, a situation which is unlikely in the ISM. Indeed, from the final interstellar yield of only 4 monolayers (ML) obtained after $2 \times 10^{5} \mathrm{yr}$, it was concluded that conversion of $\mathrm{CO}$ to $\mathrm{CH}_{3} \mathrm{OH}$ ice must occur simultaneously with the freeze-out and building up of the $\mathrm{CO}$ layer, since hydrogenation after freeze-out does not result in the high methanol abundances that are observed within reasonable times. Furthermore, although hydrogen resides in dense interstellar clouds predominantly in the form of $\mathrm{H}_{2}$, a fraction is present in atomic form together with gas phase $\mathrm{CO}$, which suggests simultaneous hydrogenation and freeze-out. The present paper presents simulations of methanol formation under cold core conditions, where hydrogenation and freezing out of the $\mathrm{CO}$ both occur. These conditions also pertain to the outer envelopes of YSO's. Different temperatures and initial abundances are used and the results are compared with observational data on the $\mathrm{H}_{2} \mathrm{CO} / \mathrm{CH}_{3} \mathrm{OH}$ gas and ice abundance ratios. The laboratory results will further be extrapolated to lower temperatures, which are more relevant to cold dense cores.

The models presented in this paper differ from previous models on the formation of interstellar methanol ice in that they include details of the surface structure of $\mathrm{CO}$ and utilise parameters obtained to reproduce experiments in the laboratory setting (Fuchs et al. 2009). In this manner, a set of energy barriers for the different processes on the surface - diffusion, desorption and reaction - was obtained, which can now be used in an interstellar environment. Unlike the master equation (Stantcheva et al. 2002), rate equation (Ruffle \& Herbst 2000), and macroscopic Monte Carlo (Ruffle \& Herbst 2000) studies of methanol formation, the continuous-time, random-walk (CTRW) Monte Carlo technique accounts for the layering of the CO. This layering is crucial, because the constant addition of fresh $\mathrm{CO}$ tends to protect the underlying layers from hydrogenation and limits the time available for reaction. Moreover, our current approach is different from previous CTRW-Monte Carlo simulations on this system (Chang et al. 2007), both because we use newly determined barriers, and because we account for the actual crystal structure of $\mathrm{CO}$ ice, instead of utilising a simple cubic structure. On the other hand, the previous study of Chang et al. (2007) coupled the gas-phase chemistry with grain-surface chemistry and used a larger grain surface reaction network.

The paper is organised in the following way. The next section describes the Monte Carlo method and introduces the input parameters of the model and their origin. Section 3 presents the model results for interstellar conditions covering the same temperature regime as in the experiments (12.0-16.5 K) (Fuchs et al. 2009). The focus of the discussion is on how the abundances depend on various parameters, especially the gas-to-dust ratio, and on the ice structure and layering. Section 3.4 extends the model to lower temperatures of 8 and $10 \mathrm{~K}$, which are more appropriate for cold dense cores. In Sect. 4 the model results are compared to a rate equation model using similar input parameters and conditions, an analytical steady-state model, other prior grain surface models, and observations. Section 5 discusses the effect of the limited chemical network on the results by introducing more reactions.

\section{Monte Carlo method}

The CTRW method has been described previously (see, e.g., Chang et al. 2005). A detailed overview of the Monte Carlo program and its input parameters can be found in Fuchs et al. (2009). In brief, the technique simulates a sequence of processes that can occur on a grain surface, which is modelled as a lattice with the number of lattice sites determined by the size of the grain and the site density for the adsorbate $\mathrm{CO}$. The order of this sequence is determined by means of a random number generator in combination with the rates for the different processes. These processes include deposition onto the surface, hopping from one lattice site to a nearest neighbour, desorption of the surface species, and reactions between two species. We assume that the (first-order) rate coefficients $\left(\mathrm{s}^{-1}\right)$ for hopping and desorption are thermally activated according to the formula

$$
R_{X}=v \exp \left(-\frac{E_{X}}{T}\right)
$$

where $v$ is the pre-exponential factor, which is approximated by a constant value obtained from the transition state theory expression $k T / h \sim 2 \times 10^{11} \mathrm{~s}^{-1}$ at low temperature (see Eq. (4.45) in Kolasinski 2002), and $E_{X}$ is the barrier (or simple endoergicity) for process $X$ in $\mathrm{K}$. These energies can be constrained by reproducing the laboratory results at different temperatures or obtained via ab-initio calculations. Unlike desorption and hopping, the rate coefficients for those chemical reactions that have an activation energy barrier also have a tunnelling component. In previous CTRW Monte Carlo studies (Chang et al. 2007; Cuppen \& Herbst 2007), we treated reactions with barriers solely by tunnelling through a square potential and ignored any small 
Table 1. Reaction rate coefficients, $R_{\text {react }}$, and activation energy barriers for $\mathrm{CO}+\mathrm{H}$ and $\mathrm{H}_{2} \mathrm{CO}+\mathrm{H}$ for different temperatures.

\begin{tabular}{ccccc}
\hline \hline$T$ & \multicolumn{2}{c}{$\mathrm{CO}+\mathrm{H}$} & \multicolumn{2}{c}{$\mathrm{H}_{2} \mathrm{CO}+\mathrm{H}$} \\
& Barrier & $R_{\text {react }}$ & Barrier & $R_{\text {react }}$ \\
$(\mathrm{K})$ & $(\mathrm{K})$ & $\left(\mathrm{s}^{-1}\right)$ & $(\mathrm{K})$ & $\left(\mathrm{s}^{-1}\right)$ \\
\hline 12.0 & $390 \pm 30$ & $2 \times 10^{-3}$ & $415 \pm 30$ & $2 \times 10^{-4}$ \\
13.5 & $435 \pm 40$ & $2 \times 10^{-3}$ & $435 \pm 40$ & $2 \times 10^{-3}$ \\
15.0 & $480 \pm 50$ & $3 \times 10^{-3}$ & $470 \pm 50$ & $5 \times 10^{-3}$ \\
16.5 & $520 \pm 60$ & $4 \times 10^{-3}$ & $490 \pm 60$ & $2 \times 10^{-2}$ \\
\hline
\end{tabular}

temperature dependence at low temperatures. The present paper uses reaction rate coefficients that have a slight temperature dependence, which were obtained in Fuchs et al. (2009) by using the rate expression for thermal activation (Eq. (2)) and allowing the activation energy barrier for reaction to be temperature dependent. Table 1 lists the resulting barrier heights and reaction rate coefficients for the reactions $\mathrm{H}+\mathrm{CO}$ and $\mathrm{H}+\mathrm{H}_{2} \mathrm{CO}$ at temperatures from $12.0 \mathrm{~K}$ to $16.5 \mathrm{~K}$. The barriers increase by $\sim 20 \%$ from the lowest to the highest temperature. Since the intermediate products, $\mathrm{HCO}$ and $\mathrm{H}_{3} \mathrm{CO}$, were not experimentally observed, it was concluded that the hydrogenation reactions of these species have a negligible barrier. In the program, these two reactions proceed without any barrier at all. After a reaction, the formed product gains some energy to rearrange and it is allowed to make a few diffusion steps.

The desorption, or binding, energy for an adsorbate depends on an energy parameter $E$. To understand the role of this parameter, let us first consider a CO molecule either in the ice or adsorbing onto the surface. The $\mathrm{CO}$ molecule is assumed to lie or stick in a configuration close to the $\alpha$-CO structure (Vegard 1930). In this configuration, each $\mathrm{CO}$ molecule has up to 14 neighbours to which hopping can occur, four in the same layer, four one layer above and below and one two layers above and below. The binding energy $E_{\text {bind }}$ is determined by the additive energy contributions of the occupied neighbouring sites. The contributions are $2 E$ for the layers below and, if applicable, $E$ for the neighbours in the same layer (lateral bonds) or in upper layers. An alternative treatment for sites below the particle is to add a single overall contribution for longer range interactions from the ice layer. In this way, the added long range contribution is roughly the same for all species of the same kind, regardless of their very local environment. However, if a very porous structure forms, the lower neighbouring sites are most likely not all occupied and the added long range contribution is less, reflecting the "real" long range contribution. As an example, if a $\mathrm{CO}$ molecule lands on top of a $\mathrm{CO}$ layer in a multi-layered $\mathrm{CO}$ ice, its binding energy is $1\left(2 E_{\mathrm{CO}-\mathrm{CO}}\right)+4\left(2 E_{\mathrm{CO}-\mathrm{CO}}\right)=10 E_{\mathrm{CO}-\mathrm{CO}}$, while if it lies in a deeply embedded layer in the ice, its binding energy is the full $1\left(2 E_{\mathrm{CO}-\mathrm{CO}}\right)+4\left(2 E_{\mathrm{CO}-\mathrm{CO}}\right)+4\left(E_{\mathrm{CO}-\mathrm{CO}}\right)+$ $4\left(E_{\mathrm{CO}-\mathrm{CO}}\right)+1\left(E_{\mathrm{CO}-\mathrm{CO}}\right)=19 E_{\mathrm{CO}-\mathrm{CO}}$. From ab-initio calculations (Andersson, in prep.) the parameter $E_{\mathrm{CO}-\mathrm{CO}}$ for $\mathrm{CO}$ is $63 \mathrm{~K}$, so that the binding energy of a $\mathrm{CO}$ adsorbate onto $\mathrm{CO}$ ice is $630 \mathrm{~K}$. Experimentally a desorption energy of $\mathrm{CO}$ from a $\mathrm{CO}$ surface was determined to be $855 \pm 25 \mathrm{~K}$, which corresponds to $13-14 E_{\mathrm{CO}-\mathrm{CO}}$. For atomic hydrogen, $E_{\mathrm{H}-\mathrm{CO}}$ was calculated to be $32 \mathrm{~K}$ onto $\mathrm{CO}$ ice (Andersson, in prep.). For $\mathrm{H}_{2}$ a value of $E_{\mathrm{H}_{2}-\mathrm{CO}}=33 \mathrm{~K}$ is used, slightly higher than for $\mathrm{H}$ as expected from calculations of Hornekær et al. (2005) for $\mathrm{H}_{2}$ and Al-Halabi \& van Dishoeck (2007) for $\mathrm{H}$ atoms. If lattice sites are occupied by heavier species than $\mathrm{CO}$ (mainly $\mathrm{CH}_{3} \mathrm{OH}$ ) the total binding energy of an $\mathrm{H}$ or $\mathrm{CO}$, and the structure are assumed not to change. If lattice sites are occupied by $\mathrm{H}$ atoms rather than
Table 2. The energy parameter $E$ for the different species.

\begin{tabular}{lrr}
\hline \hline Species & $\begin{array}{r}\mathrm{H} \\
(\mathrm{K})\end{array}$ & $\begin{array}{r}\mathrm{CO} \\
(\mathrm{K})\end{array}$ \\
\hline $\mathrm{H}$ & 3 & 32 \\
$\mathrm{H}_{2}$ & 3 & 33 \\
$\mathrm{CO}$ & 32 & 63 \\
$\mathrm{HCO}$ & 160 & 1600 \\
$\mathrm{H}_{2} \mathrm{CO}$ & 160 & 1600 \\
$\mathrm{H}_{3} \mathrm{CO}$ & 160 & 1600 \\
$\mathrm{CH}_{3} \mathrm{OH}$ & 160 & 1600 \\
\hline
\end{tabular}

$\mathrm{CO}$, the lower value of $E_{\mathrm{X}-\mathrm{H}}$ is used for those relevant sites, so that the total binding energy for a specific $\mathrm{CO}$ is an expression containing both the parameters for $\mathrm{CO}$ and for $\mathrm{H}$. For atomic $\mathrm{H}$, the van der Waals interaction with another atomic $\mathrm{H}$ in an adjoining site is rather small, i.e., $E_{\mathrm{H}-\mathrm{H}}=E_{\mathrm{H}-\mathrm{CO}} / 10$. The energy parameters $E_{\mathrm{X}-\mathrm{CO}}$ for $\mathrm{H}_{2} \mathrm{CO}$ and $\mathrm{CH}_{3} \mathrm{OH}$ and the intermediates, $\mathrm{HCO}$ and $\mathrm{H}_{3} \mathrm{CO}$, are chosen such that these species neither desorb nor diffuse (see below) from the grain at the temperatures studied. All adopted values for $E$ are summarised in Table 2.

The same parameter $E$ is used to help determine the hopping barrier from site $i$ to an empty adjacent site, $j$. If sites $i$ and $j$ have the same binding energy, then the barrier for hopping is given by the equation

$E_{\mathrm{hop}}(i, j)=\xi E$,

where $\xi$ is a parameter that determines how high the barrier is compared with the binding energy. Here $\xi=8$ is used, so that the barrier height is $80 \%$ of the binding energy of a surface adsorbate (see above). As reported in Fuchs et al. (2009), the model results are relatively insensitive to the exact value of this parameter. In general, the effect of the diffusion rate was found to become larger with temperature, where faster diffusion results in less effective hydrogenation, since the residence time per site decreases and more $\mathrm{H}$ atoms will desorb. The value of $\xi=8$ was chosen to result in acceptable simulation times and to reproduce the desorption energy/hopping barrier ratio found by Katz et al. (1999) for $\mathrm{H}$ and $\mathrm{H}_{2}$ on silicates and amorphous carbon. The same parameter $\xi$ is used for all different species: since it is multiplied by the species-specific parameter $E$, the difference in hopping rates between species is automatically accounted for. For this choice of $\xi, \mathrm{H}$ and $\mathrm{H}_{2}$ are mobile for $T>8 \mathrm{~K}$ and $\mathrm{CO}$ for $T>16.5 \mathrm{~K}$. Diffusion from low to high binding sites is possible from even lower temperatures.

If the binding sites $i$ and $j$ have different binding energies, we add a second term to the formula for the hopping barrier in order to have the forward and backward rates obey detailed balance. The overall expression then becomes

$E_{\mathrm{hop}}(i, j)=\xi E+\frac{\Delta E_{\mathrm{bind}}(i, j)}{2}$,

where $\Delta E_{\text {bind }}(i, j)$ is the difference in binding energy between the two sites. Diffusion into the structure of the ice is included as well. Minimum energy path calculations suggest that $\mathrm{CO}$ and $\mathrm{H}$ can swap positions, enabling an adsorbing $\mathrm{H}$-atom to penetrate into the CO ice (Andersson, in prep.). The barrier for this process strongly depends on the layer in which the $\mathrm{H}$-atom is situated. In the simulations the barrier for this event is $\left(350+5\left(z_{1}+z_{2}\right)\right) \mathrm{K}$ for an H-atom to swap between layers $z_{1}$ and $z_{2}$, where $z_{i}$ stands for the depth of the atom in ML. This swapping mechanism was only found to occur for the top few layers, where there is more space to accommodate the movement involved in the swap 
(Andersson, in prep.). The minimum energy path calculations do not include thermal effects, which could promote this mechanism by lowering the barrier in the upper layers. In the current implementation, the layer dependence of the swapping barriers effectively limits the swapping process to the top few layers. Deeper into the ice, the swapping mechanism is not thermally accessible. Hydrogen diffusion throught the ice via interstitial sites was found not to reproduce laboratory results and is therefore not included.

Thus, each species can in principle undergo up to 15 processes: thermal desorption and hopping to one of the up to 14 neighbouring sites, or, if sites are occupied, reaction with the species in that site. Reactions without activation energy (e.g., $\mathrm{H}+\mathrm{HCO} \rightarrow \mathrm{H}_{2} \mathrm{CO}$ ) occur with $100 \%$ efficiency, whereas for reactions with barriers, we must simulate the competition between the efficiency of reaction and that of hopping out of the adjacent lattice sites. Some of these processes can be forbidden. Bulk species are, for instance, not allowed to desorb and not all species react with each other. The rate coefficients of all these processes are determined using Eq. (2) and the barriers as discussed above. In this way, diffusion and reaction are automatically treated competitively.

In addition to reactions occurring via the LangmuirHinshelwood mechanism, which happen as a result of diffusion into adjacent sites, the program includes reactions occurring via the Eley-Rideal mechanism, in which a gas-phase species lands atop a surface species and reacts with it. The barriers for reactions are assumed to be independent of mechanism. In the diffusive case, however, if two reactants do not tunnel under or cross over the activation energy barrier, they have multiple additional opportunities until they diffuse away from one another. In the Eley-Rideal case, we allow only one opportunity. For example, an $\mathrm{H}$ atom landing directly atop a $\mathrm{CO}$ molecule gets one chance to overcome the reaction barrier and react. If the reaction does not proceed, the $\mathrm{H}$ atom can then hop further to find another reactant.

Deposition onto a surface site occurs with a rate coefficient $R_{\text {dep }}$ according to

$R_{\text {dep }}=\frac{v_{\mathrm{A}} n_{\mathrm{A}}}{4 \rho}$,

where $n_{\mathrm{A}}$ is the absolute gas abundance of species A, $\rho$ is the surface site density, and $v_{\mathrm{A}}$ is the mean velocity of species $\mathrm{A}$ :

$v_{\mathrm{A}}=\sqrt{\frac{8 k T_{\mathrm{gas}}}{\pi m_{\mathrm{A}}}}$,

with $T_{\text {gas }}$ the temperature of the gas and $m_{\mathrm{A}}$ the mass of A. We use the standard value of $\rho=1 \times 10^{15} \mathrm{~cm}^{-2}$ which agrees with the site density of the $\alpha$-CO (110) crystal face. During the simulation $\mathrm{H}, \mathrm{CO}$ and $\mathrm{H}_{2}$ are allowed to deposit on the surface. We use a molecular hydrogen abundance that is only slightly higher than the atomic hydrogen abundance to maintain a coverage of $\mathrm{H}_{2}$ on the surface within a reasonable simulation time. The presence of $\mathrm{H}_{2}$, which is also formed on the surface, has an effect on the penetration of the atoms and the diffusion. The CO gas-phase abundance is adjusted to account for freeze-out during the simulation. This freeze-out rate (loss rate of gaseous CO), which is the deposition rate onto a surface site multiplied by the number of sites per grain and the grain concentration, depends upon the dust-togas number ratio for fixed gas-phase density $n_{\mathrm{H}}$. This paper uses two values for this parameter: $1 \times 10^{-12} n_{\mathrm{H}}$ and $2 \times 10^{-12} n_{\mathrm{H}}$. The influence of the rate of depletion, i.e., the rate of disappearance of CO from the gas, is discussed in Sect. 3.2. Gas-phase chemistry is not included here.

\section{Results}

\subsection{Ice abundances as functions of time}

In order to follow the build up of $\mathrm{CO}, \mathrm{H}_{2} \mathrm{CO}$, and $\mathrm{CH}_{3} \mathrm{OH}$ in the ice mantle, simulations at different temperatures and densities were carried out. All simulations commence with the same initial bare surfaces consisting of lattices with $50 \times 50$ sites and some simple surface steps (similar to Surface $c$ in Cuppen \& Herbst 2005). The choice of the initial surface (either silicates or amorphous carbon) was found to be unimportant after the buildup of a few monolayers of ice. To start the simulation on a bare surface, the energy parameters used were chosen to be the same as for the $\mathrm{CO}$ surface. All results were converted to grains with a standard size of $0.1 \mu \mathrm{m}$. The simulation surface is a square flat surface. The spherical, continuous nature of a grains is mimicked by periodic boundary conditions. The size of the simulated surface has been found to be in the regime where no size effects are observed (Chang et al. 2005); this regime is associated with surface abundances of reactive species such as $\mathrm{H}$ larger than one per grain. For $\mathrm{H}_{2}$ formation, a size dependence is observed, since for smaller grains the average surface density of atomic hydrogen is much smaller than one (accretion limit), but because of the stronger sticking of $\mathrm{CO}$ and $\mathrm{H}_{2} \mathrm{CO}$ with respect to $\mathrm{H}$ atoms, the size dependence is probably only important for higher temperatures where $\mathrm{CO}$ and $\mathrm{H}_{2} \mathrm{CO}$ start to desorb.

Figure 1 shows the evolution of the three dominant ice species as a function of time for $n_{\mathrm{H}}=1 \times 10^{4} \mathrm{~cm}^{-3}, n_{\text {grain }}=$ $2 \times 10^{-12} n_{\mathrm{H}}$ and four different temperatures: $12.0,13.5,15.0$, and $16.5 \mathrm{~K}$. These temperatures are the same as used in the experiments in Fuchs et al. (2009). The abundances are plotted in terms of $10^{15}$ molecules per $\mathrm{cm}^{-2}$, which is equivalent to species per lattice site. The plotted curves are the combined results of several independent simulations using different initial seeds, e.g., initial settings of the random number generator. Simulations were added until the evolution did not significantly change. Initial gas phase abundances of $n(\mathrm{CO})=1 \times 10^{-4} n_{\mathrm{H}}$ and $n(\mathrm{H})=1 \times 10^{-4} n_{\mathrm{H}}$ were assumed; these correspond to observed (CO) (Lacy et al. 1994) and calculated $(\mathrm{H})$ fractional abundances for cold dense cores of a density of $n_{\mathrm{H}}=1 \times 10^{4} \mathrm{~cm}^{-3}$. The abundance of atomic $\mathrm{H}$ is mainly determined by the ration between the cosmicray destruction rate of $\mathrm{H}_{2}$ and the formation rate of $\mathrm{H}_{2}$ which leads to $\sim 1 \mathrm{~cm}^{-3}$ independent of the density (Duley \& Williams 1984). Goldsmith \& Li (2005) showed observationally that the $\mathrm{H}$-atom abundance is higher than $1 \mathrm{~cm}^{-3}$ and we therefore use a higher $\mathrm{H}$ abundance of $10 \mathrm{~cm}^{-3}$ for our high density case which will be discussed below. The gas-phase abundance of $\mathrm{CO}$ is allowed to deplete as $\mathrm{CO}$ accretes onto grains while the gas-phase abundance of $\mathrm{H}$ remains constant. The solid line indicates the combined ice build-up of the three species together; in $10^{5} \mathrm{yr}$, at most 10 monolayers of ice are produced at the value of $n_{\mathrm{H}}$ used. From the graphs, a difference in this total build-up for the higher temperatures is immediately clear. Whereas the ice thickness grows linearly for 12.0 and $13.5 \mathrm{~K}$, a clear non-linear behaviour as well as a drop in the total coverage can be observed at 15.0 and especially $16.5 \mathrm{~K}$. This is due to the binding energy of $\mathrm{CO}$. The residence time of an adsorbed $\mathrm{CO}$ molecule is $0.3 \mathrm{yr}$ on a flat grain at $16.5 \mathrm{~K}$. This time will increase once the $\mathrm{CO}$ molecules can stick together and form small islands, because the binding within the islands is stronger than for individual molecules. With the CO gas-phase concentration of $1 \mathrm{~cm}^{-3}$, 


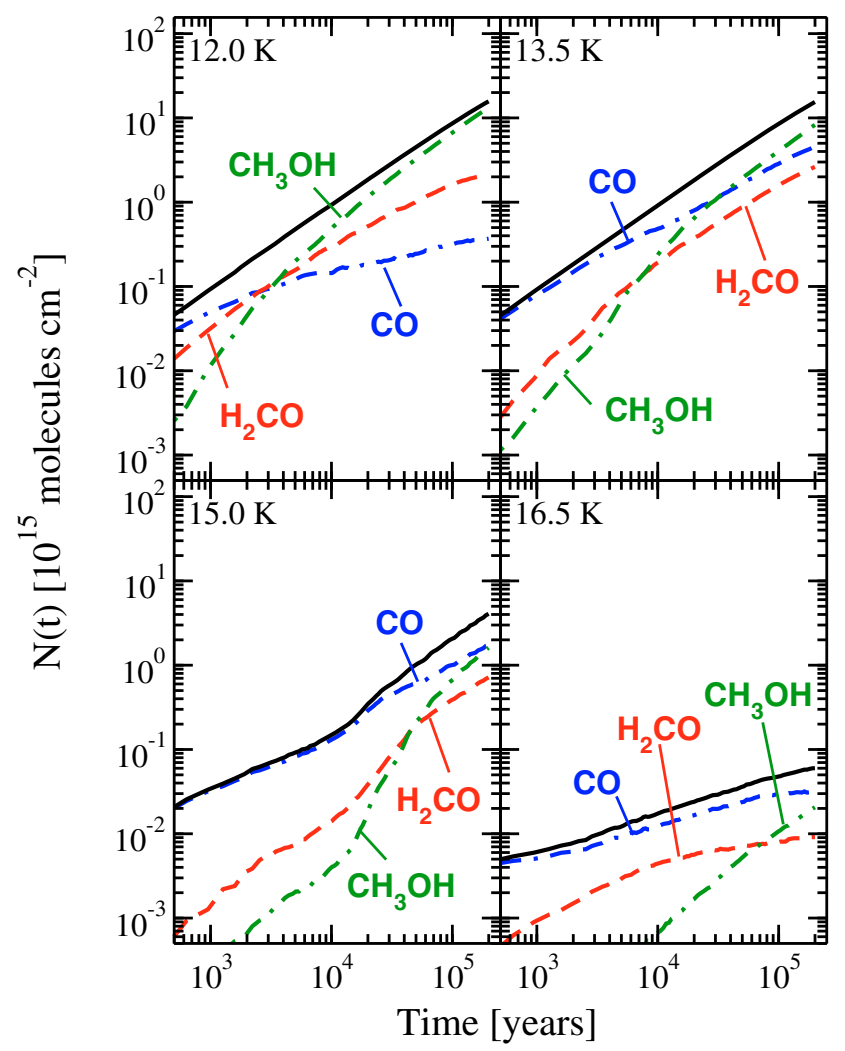

Fig. 1. $\mathrm{CO}, \mathrm{H}_{2} \mathrm{CO}$, and $\mathrm{CH}_{3} \mathrm{OH}$ build-up as a function of time for a density of $n_{\mathrm{H}}=10^{4} \mathrm{~cm}^{-3}, n_{\text {grain }}=2 \times 10^{-12} n_{\mathrm{H}}$ and $n(\mathrm{CO}) / n(\mathrm{H})=$ 1 at four different surface temperatures a) 12.0 , b) 13.5 , c) 15.0 and d) $16.5 \mathrm{~K}$. The black line indicates the total ice thickness, i.e. the sum of the $\mathrm{CO}, \mathrm{H}_{2} \mathrm{CO}$, and $\mathrm{CH}_{3} \mathrm{OH}$ abundances.

the arrival time of new $\mathrm{CO}$ molecules onto a grain is of similar order as the residence time on a bare surface, so that the $\mathrm{CO}$ molecules do not have the opportunity to meet and stick together to form small islands, which is an efficient mechanism for growth. Figure 2 shows similar time evolution curves for a density of $n_{\mathrm{H}}=1 \times 10^{5} \mathrm{~cm}^{-3}$, leading to a ten times higher flux, and indeed here there is a greater ice build-up at $16.5 \mathrm{~K}$.

In general, the production of $\mathrm{H}_{2} \mathrm{CO}$ and $\mathrm{CH}_{3} \mathrm{OH}$ decreases with increasing temperature for both densities. This dependence is in agreement with the laboratory experiments of the hydrogenation of a CO ice by Fuchs et al. (2009). There the initial production rate was observed to be higher for low temperature whereas the final yield at the end of the experiments peaked at 15.0 K due to an increase of the penetration depth of $\mathrm{H}$-atoms into the $\mathrm{CO}$ ice with temperature. In the co-deposition simulations presented in this paper, the penetration depth has less impact on the formation of $\mathrm{H}_{2} \mathrm{CO}$ and $\mathrm{CH}_{3} \mathrm{OH}$ since a fresh supply of $\mathrm{CO}$ is constantly deposited and the formation rate is therefore more comparable to the rate at the start of the experiments when a pure $\mathrm{CO}$ ice is exposed to atomic hydrogen. In this condition, it is the shortened grain lifetime of $\mathrm{H}$ atoms at the higher temperatures that reduces the rate of methanol formation from CO. The rate for reaction changes only minimally with increasing temperature.

The pure CO build-up here peaks at $13.5 \mathrm{~K}$ for both densities as can be clearly seen in Figs. 1 and 2 by comparing the dash-dotted curves. This quantity is influenced by two effects with opposite temperature dependence: the desorption of $\mathrm{CO}$ molecules (see above), which increases with increasing temperature, and the conversion of $\mathrm{CO}$ into $\mathrm{H}_{2} \mathrm{CO}$, which decreases

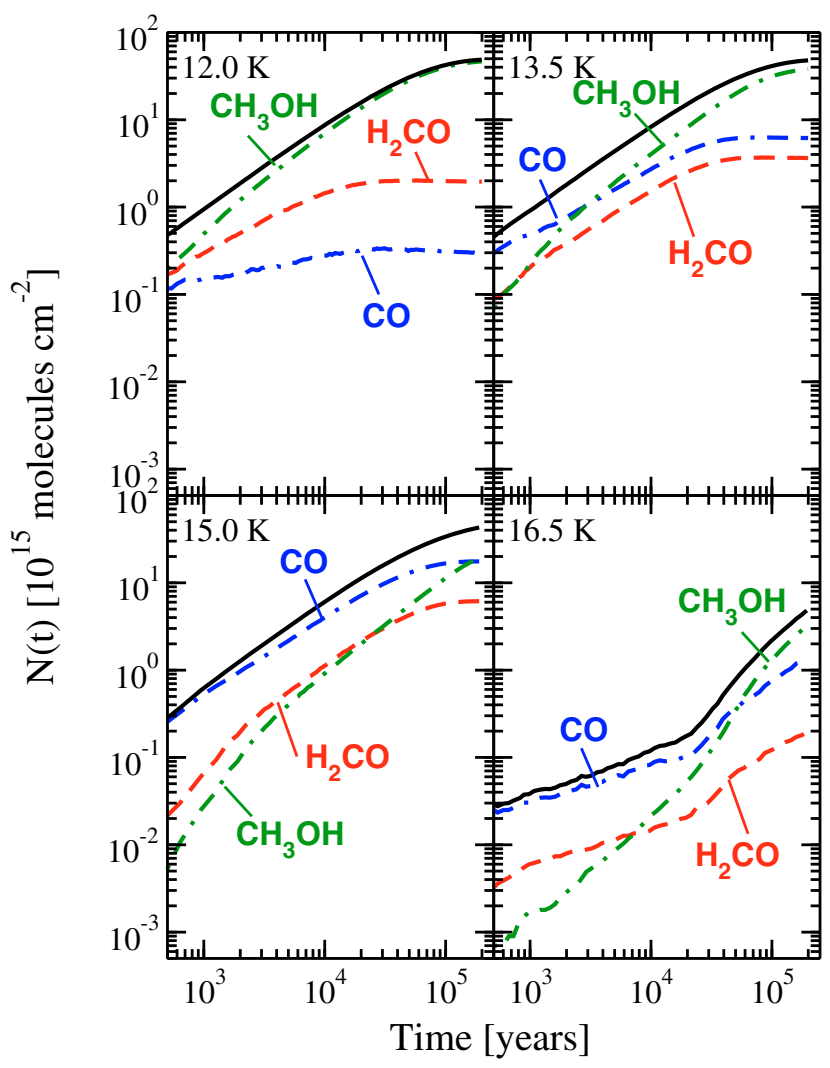

Fig. 2. Similar to Fig. 1 for $n_{\mathrm{H}}=10^{5} \mathrm{~cm}^{-3}$.

with increasing temperature because of the lessened ability of $\mathrm{H}$ atoms to remain on grains long enough to react. Nevertheless, for most conditions, $\mathrm{CH}_{3} \mathrm{OH}$ dominates the ice layer at late times and exhibits a very steep formation curve. $\mathrm{CO}$ and $\mathrm{H}_{2} \mathrm{CO}$ on the other hand start with a high abundance at early times and increase much more slowly, even reaching a steady-state level on some occasions. The steady-state can be clearly seen for $T=12.0$ and $13.5 \mathrm{~K}$ for $n_{\mathrm{H}}=1 \times 10^{5} \mathrm{~cm}^{-3}$ and $T=16.5 \mathrm{~K}$ for $n_{\mathrm{H}}=1 \times 10^{4} \mathrm{~cm}^{-3}$. For lower atomic $\mathrm{H}$ abundances, $\sim 1 \mathrm{~cm}^{-3}$, the $\mathrm{H}_{2} \mathrm{CO}$ and $\mathrm{CH}_{3} \mathrm{OH}$ formation is expected to occur at later times, since similar $n(\mathrm{H}) / n(\mathrm{CO})$ ratios will occur at later times.

\subsection{Dust-to-gas number ratio}

The dust-to-gas number ratio determines the rate of the gas phase depletion and the maximum ice thickness that can be achieved before depletion of gaseous $\mathrm{CO}$, which is roughly $50 \mathrm{ML}$ for $n_{\text {grain }}=2 \times 10^{-12} n_{\mathrm{H}}$ and $100 \mathrm{ML}$ for $n_{\text {grain }}=1 \times 10^{-12} n_{\mathrm{H}}$ as is discussed in the next section.

Figure 3 shows the temporal evolution of $\mathrm{CO}, \mathrm{H}_{2} \mathrm{CO}$ and $\mathrm{CH}_{3} \mathrm{OH}$ for 12.0 and $16.5 \mathrm{~K}$ with a reduced dust-to-gas ratio of $1 \times 10^{-12} n_{\mathrm{H}}$. Densities of $n_{\mathrm{H}}=10^{4}$ and $10^{5} \mathrm{~cm}^{-3}$ are used. Panel (a) can be compared with the $12.0 \mathrm{~K}$ panel in Fig. 1a, panel (b) with the $16.5 \mathrm{~K}$ panel in Fig. 1 and panels (c) and (d) with the 12.0 and $16.5 \mathrm{~K}$ panels in Fig. 2, respectively. It is apparent that only Fig. $3 \mathrm{c}$ is significantly different from its analogs. For the lower density cases $\left(n_{\mathrm{H}}=10^{4} \mathrm{~cm}^{-3}\right)$, substantial depletion of gaseous $\mathrm{CO}$ has not started yet after $2 \times 10^{5} \mathrm{yr}$, resulting in roughly the same gas-phase composition throughout the simulation for both dust-to-gas ratios. This is generally not true for the higher density models. At $16.5 \mathrm{~K}$, however, the build-up of ice layers is hampered by the desorption of $\mathrm{CO}$ back into the gas phase, again resulting in very similar accretion rates for the two 


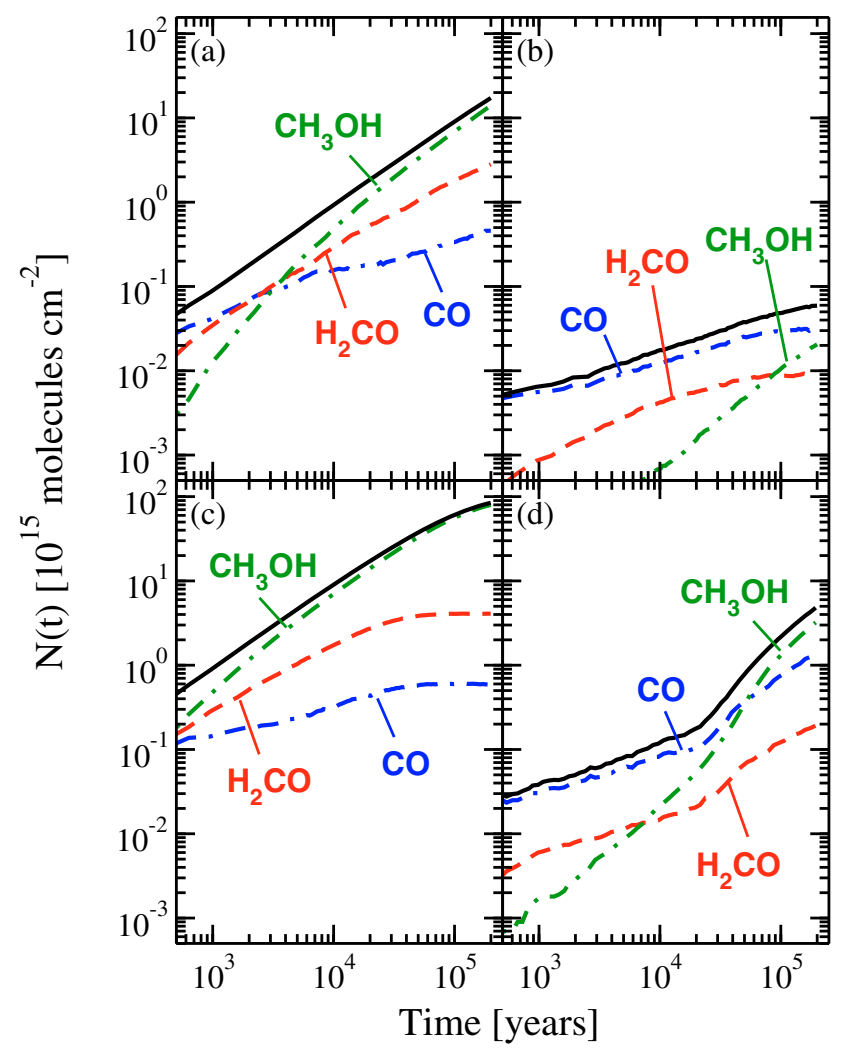

Fig. 3. $\mathrm{CO}, \mathrm{H}_{2} \mathrm{CO}$, and $\mathrm{CH}_{3} \mathrm{OH}$ build-up as a function of time for $n_{\text {grain }}=1 \times 10^{-12} n_{\mathrm{H}}$ and $n(\mathrm{CO}) / n(\mathrm{H})=1$. a) $T=12.0 \mathrm{~K}$ and $n_{\mathrm{H}}=10^{4} \mathrm{~cm}^{-3}$, b) $T=16.5 \mathrm{~K}$ and $n_{\mathrm{H}}=10^{4} \mathrm{~cm}^{-3}$, c) $T=12.0 \mathrm{~K}$ and $n_{\mathrm{H}}=10^{5} \mathrm{~cm}^{-3}$, and d) $T=16.5 \mathrm{~K}$ and $n_{\mathrm{H}}=10^{5} \mathrm{~cm}^{-3}$.

dust-to-gas cases. At lower temperatures, however, the accretion rate for $\mathrm{CO}$ is greater for the lower dust-to-gas case. The main difference between Figs. $2 \mathrm{a}(12.0 \mathrm{~K})$ and $3 \mathrm{c}$ is indeed that the levelling off to constant values for $\mathrm{CO}$ and $\mathrm{H}_{2} \mathrm{CO}$ occurs at later times and thicker ice layers for $n_{\text {grain }}=1 \times 10^{-12} n_{\mathrm{H}}$.

\subsection{Ice structure}

In addition to the overall surface abundance as a function of time, the Monte Carlo approach allows us to obtain more detailed information concerning the layering of the ice. Figure 4 plots the fraction per monolayer of the main ice components $\mathrm{CO}, \mathrm{H}_{2} \mathrm{CO}$ and $\mathrm{CH}_{3} \mathrm{OH}$ at a time of $2 \times 10^{5} \mathrm{yr}$ for $12.0 \mathrm{~K}(\mathrm{a}, \mathrm{b}, \mathrm{d})$ ) and $15.0 \mathrm{~K}(\mathrm{c})$. The abscissa is the number of the monolayer starting from the bare surface as zero indicated by "grain boundary" in the figure. The label "gas phase boundary" indicates the top layer of the ice mantle, which faces the gas phase. Despite differences in dust-to-gas ratios and other parameters in the panels (see caption), the plot clearly shows that there is a gradient in the ice composition. At the onset of the $\mathrm{CO}$ freeze-out, a fraction of the layers remains in the form of $\mathrm{CO}$ and the $\mathrm{H}_{2} \mathrm{CO}$ is not fully hydrogenated to $\mathrm{CH}_{3} \mathrm{OH}$. While the gas phase $\mathrm{CO}$ slowly depletes, the $n(\mathrm{H}) / n(\mathrm{CO})$ ratio becomes more favourable for the complete hydrogenation of $\mathrm{CO}$. For example, in the $2 \times 10^{5} \mathrm{yr}$ of the simulation, the gas phase $\mathrm{CO}$ abundance drops from $10 \mathrm{~cm}^{-3}$ to $0.2 \mathrm{~cm}^{-3}$ for $12.0 \mathrm{~K}, n_{\mathrm{H}}=10^{5} \mathrm{~cm}^{-3}$ and $n_{\text {grain }}=2 \times 10^{-12} n_{\mathrm{H}}$. The right panels show the ice composition for slower CO depletion $\left(n_{\text {grain }}=1 \times 10^{-12} n_{\mathrm{H}}\right)$. Panel $(\mathrm{d})$ has additionally an altered initial abundance of $n(\mathrm{H}) / n(\mathrm{CO})=0.5$. Note that the horizontal scale for the right panels differs from that for the left panels. For $n_{\text {grain }}=1 \times 10^{-12} n_{\mathrm{H}}$ the change to pure $\mathrm{CH}_{3} \mathrm{OH}$ layers

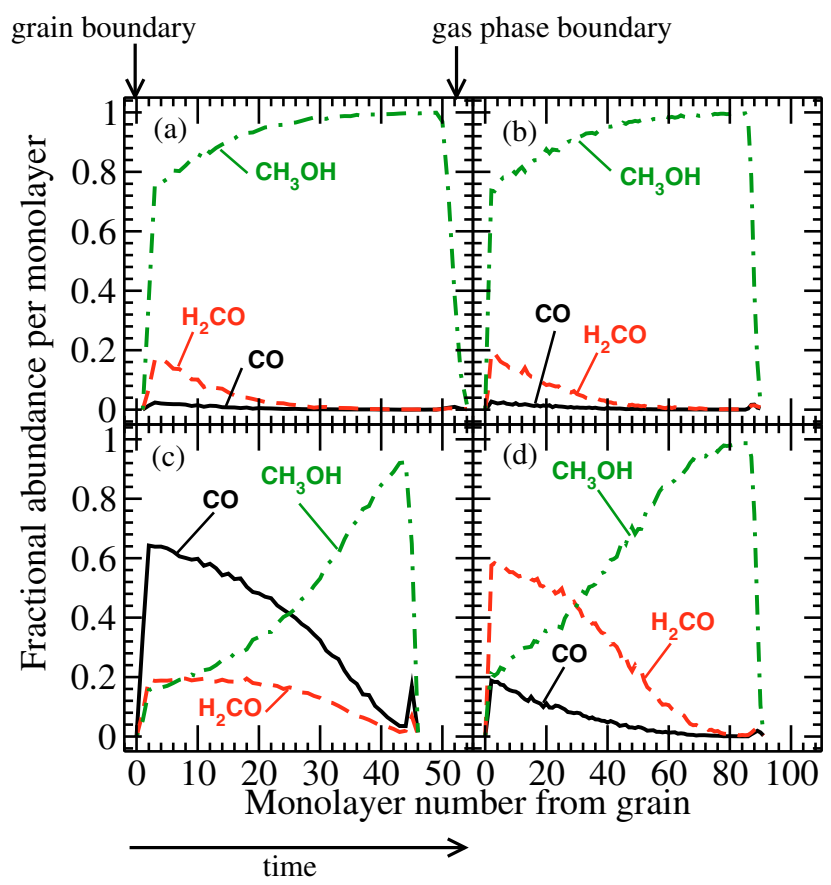

Fig. 4. Fractional abundance of the three main ice components as a function of monolayer after $2 \times 10^{5} \mathrm{yr}$ at $n_{\mathrm{H}}=10^{5} \mathrm{~cm}^{-3}$ for a) $12.0 \mathrm{~K}$ and $n_{\text {grain }}=2 \times 10^{-12} n_{\mathrm{H}}$, b) $12.0 \mathrm{~K}$ and $n_{\text {grain }}=1 \times 10^{-12} n_{\mathrm{H}}$, c) $15.0 \mathrm{~K}$ and $n_{\text {grain }}=2 \times 10^{-12} n_{\mathrm{H}}$, and d) $12.0 \mathrm{~K}$ and $n_{\text {grain }}=1 \times 10^{-12} n_{\mathrm{H}}$ with a lower initial $n(\mathrm{H}) / n(\mathrm{CO})$ gas phase abundance ratio of 0.5 .

occurs over more layers than for $n_{\text {grain }}=2 \times 10^{-12} n_{\mathrm{H}}$. If panels (a) and (b) were plotted as a function of the fraction of the total ice thickness instead of the absolute ice thickness, very similar graphs would be obtained. The final overall $\mathrm{H}_{2} \mathrm{CO} / \mathrm{CH}_{3} \mathrm{OH}$ ratio after freeze-out is therefore independent of the exact dust-to-gas ratio. Comparison of panels (a) and (c) confirms that the rate and efficiency of the conversion of $\mathrm{CO}$ into methanol is determined by the temperature while comparison of panels (b) and (d) shows that the rate and efficiency are also determined by the $n(\mathrm{H}) / n(\mathrm{CO})$ ratio. A closer look at panel (d) compared with panel (b) shows that the lower $n(\mathrm{H}) / n(\mathrm{CO})$ ratio leads to larger $\mathrm{H}_{2} \mathrm{CO}$ and $\mathrm{CO}$ fractions for the lower monolayers and that the conversion to pure methanol layers occurs only at higher layers, which are formed at later times.

Figure 5 paints a schematic picture of a grain mantle. At the onset of $\mathrm{CO}$ freeze-out, the flux of $\mathrm{CO}$ molecules accreting onto the grain is large, larger than the part of $\mathrm{H}$ atom flux that is available for hydrogenation of $\mathrm{CO}$, and, as a consequence, the mantle will be rich in $\mathrm{CO}$ with $\mathrm{H}_{2} \mathrm{CO}$ and $\mathrm{CH}_{3} \mathrm{OH}$ as minor components. As the $n(\mathrm{H}) / n(\mathrm{CO})$ ratio in the gas phase increases, more and more $\mathrm{CO}$ and $\mathrm{H}_{2} \mathrm{CO}$ is converted into $\mathrm{CH}_{3} \mathrm{OH}$ and the outer layers of the mantle become more $\mathrm{CH}_{3} \mathrm{OH}$ rich. Note that the astronomically observed solid abundances are sums over the entire grain mantle, although different ice components can be distinguished through the line profiles.

Actual simulated grain mantle cross sections for individual runs are plotted in Fig. 6. Here unoccupied sites are indicated in black, light gray on the bottom of the figures represents the bare grain, while $\mathrm{H}$ and $\mathrm{H}_{2}$ are represented by white. All other mantle species, $\mathrm{CO}, \mathrm{HCO}, \mathrm{H}_{2} \mathrm{CO}, \mathrm{H}_{3} \mathrm{CO}$, and $\mathrm{CH}_{3} \mathrm{OH}$, have different gray scale levels according to their degree of hydrogenation; i.e., $\mathrm{CH}_{3} \mathrm{OH}$ is darkest, whereas $\mathrm{CO}$ is represented by the lightest gray. The four panels correspond to the resulting icy mantle after $2 \times 10^{5}$ yr under the same conditions as in Fig. 2. The grain 


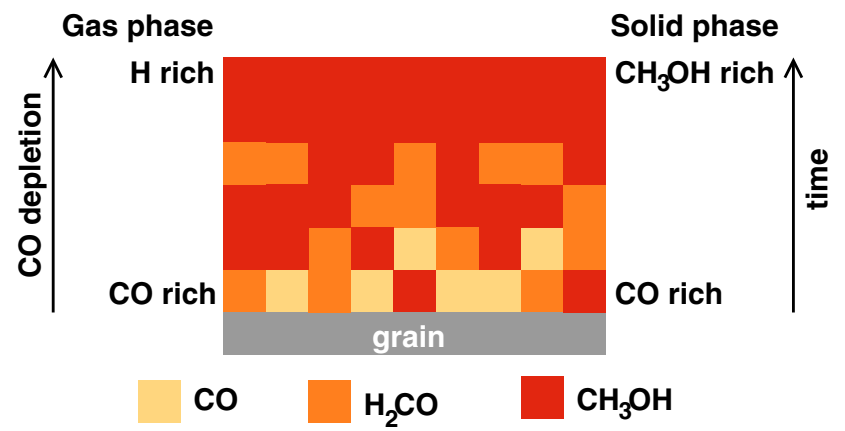

Fig. 5. Schematic picture of the growth of the ice mantle during $\mathrm{CO}$ freeze-out. For coloured figures, see the online version.

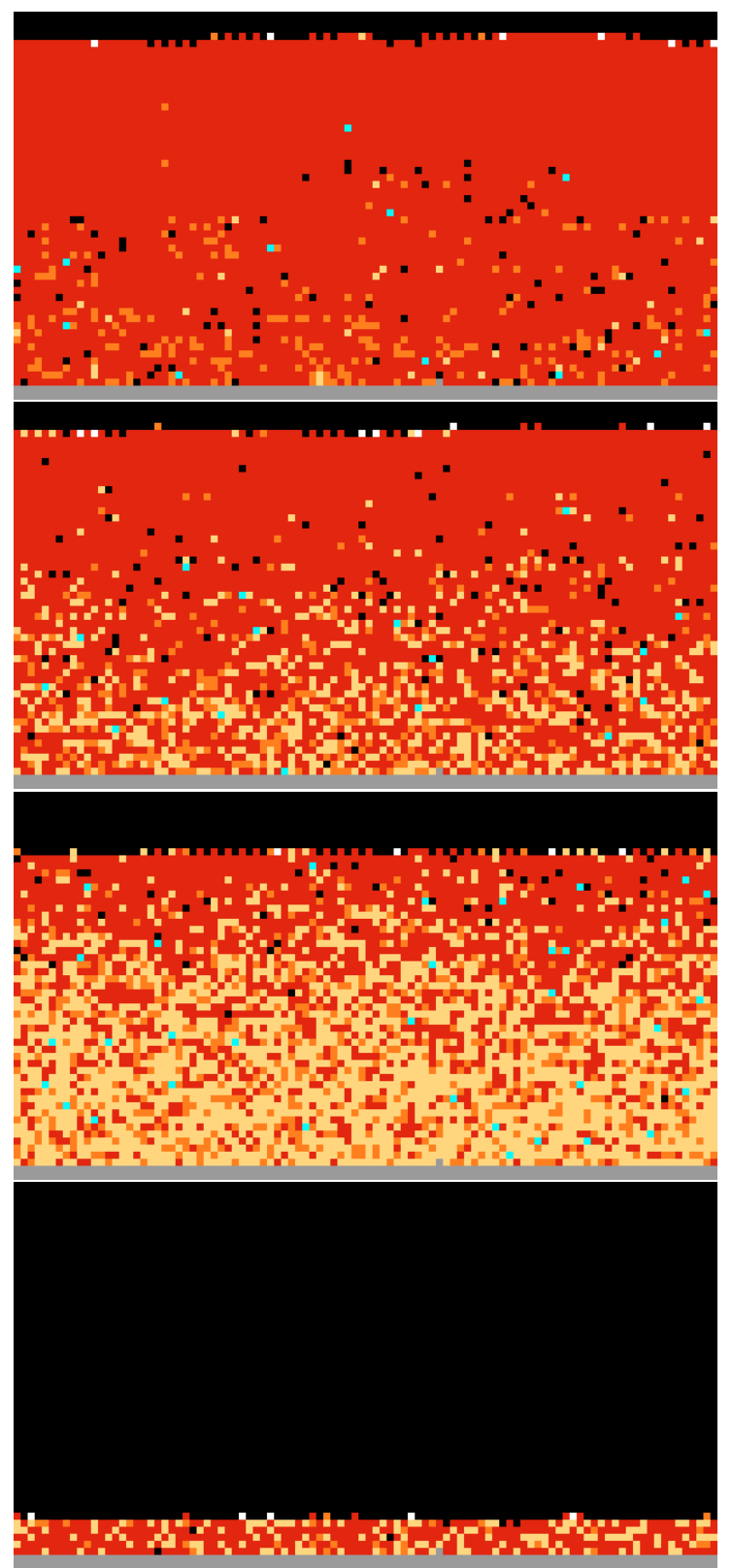

Fig. 6. Cross section of the ice mantle after $2 \times 10^{5} \mathrm{yr}$ at a density of $n_{\mathrm{H}}=10^{5} \mathrm{~cm}^{-3}$ for $12.0,13.5,15.0$ and $16.5 \mathrm{~K}$ (top to bottom). Unoccupied sites are indicated in black, grain by light grey, intermediates by cyan, and $\mathrm{H}$ and $\mathrm{H}_{2}$ by white. $\mathrm{CO}, \mathrm{HCO}, \mathrm{H}_{2} \mathrm{CO}, \mathrm{H}_{3} \mathrm{CO}$, and $\mathrm{CH}_{3} \mathrm{OH}$ are coloured by increasing darkness according to their degree of hydrogenation (see Fig. 5). For coloured figures, see the online version.

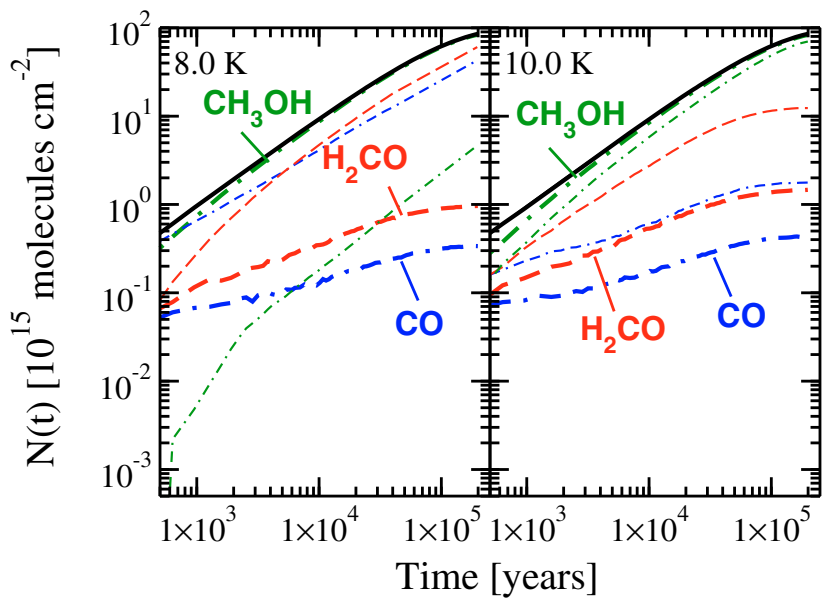

Fig. 7. $\mathrm{CO}, \mathrm{H}_{2} \mathrm{CO}$, and $\mathrm{CH}_{3} \mathrm{OH}$ build-up as a function of time for a density of $n_{\mathrm{H}}=10^{5} \mathrm{~cm}^{-3}, n_{\text {grain }}=1 \times 10^{-12} n_{\mathrm{H}}$ and $n(\mathrm{CO}) / n(\mathrm{H})=1$ at two different surface temperatures a) 8.0 , and b) $10.0 \mathrm{~K}$. The black line indicates the total ice thickness, i.e. the sum of the $\mathrm{CO}, \mathrm{H}_{2} \mathrm{CO}$, and $\mathrm{CH}_{3} \mathrm{OH}$ abundances. The reaction rates are assumed to be either governed by tunneling (thick lines) or purely thermal (thin lines).

temperatures are $12.0,13.5,15.0$ and $16.5 \mathrm{~K}$ from top to bottom. The zigzagging pattern at the grain mantle surface reflects the zigzagging structure of $\alpha$-CO. The panels show clearly the gradient in $\mathrm{CO}, \mathrm{H}_{2} \mathrm{CO}$ and $\mathrm{CH}_{3} \mathrm{OH}$ across the grain with the top layers containing the more saturated species. Furthermore, it shows that the lower temperature grains contain more $\mathrm{CH}_{3} \mathrm{OH}$. The grain mantle at $16.5 \mathrm{~K}$ is much thinner due to the desorption of $\mathrm{CO}$ at this temperature. Finally, some small pores can be observed in the mantles; these appear to form during hydrogenation where two species recombine to one, which takes up less space. It appears that at late times, when the flux is low, either $\mathrm{CO}$ or $\mathrm{CH}_{3} \mathrm{OH}$ has some time to rearrange and fill most of these vacancies.

\subsection{Methanol formation at 8 and $10 \mathrm{~K}$}

The results presented above all concern the formation of methanol in the temperature regime between 12.0 and $16.5 \mathrm{~K}$. These temperatures are more representative for the outer regions of protostellar envelopes. In cold dense cores, the temperature is most likely lower. Figure 7 presents simulation results for 8 and $10 \mathrm{~K}$. The model is extended to temperatures outside the regime studied in the laboratory, by assuming that the reaction rates $\left(R_{\text {react }}\right.$ in Table 1$)$ do not change with temperature, since they are dominated by tunnelling, whereas all other processes are thermally activated. The results in Fig. 7 clearly show that formaldehyde and methanol are still efficiently formed at these temperatures. Simulations with much lower reaction rates for $\mathrm{H}+\mathrm{CO}$ and $\mathrm{H}+\mathrm{H}_{2} \mathrm{CO}$, thermally activated using barriers of 390 and $415 \mathrm{~K}$, respectively, still result in the formation of both $\mathrm{H}_{2} \mathrm{CO}$ and $\mathrm{CH}_{3} \mathrm{OH}$, although with much lower abundances as indicated by the thin lines in Fig. 7. The abundance of formaldehyde is much larger in this case, since it is not efficiently converted into methanol. However, the rates at higher temperature suggest tunneling to be important and the abundances are therefore probably better represented by the thick curves. 


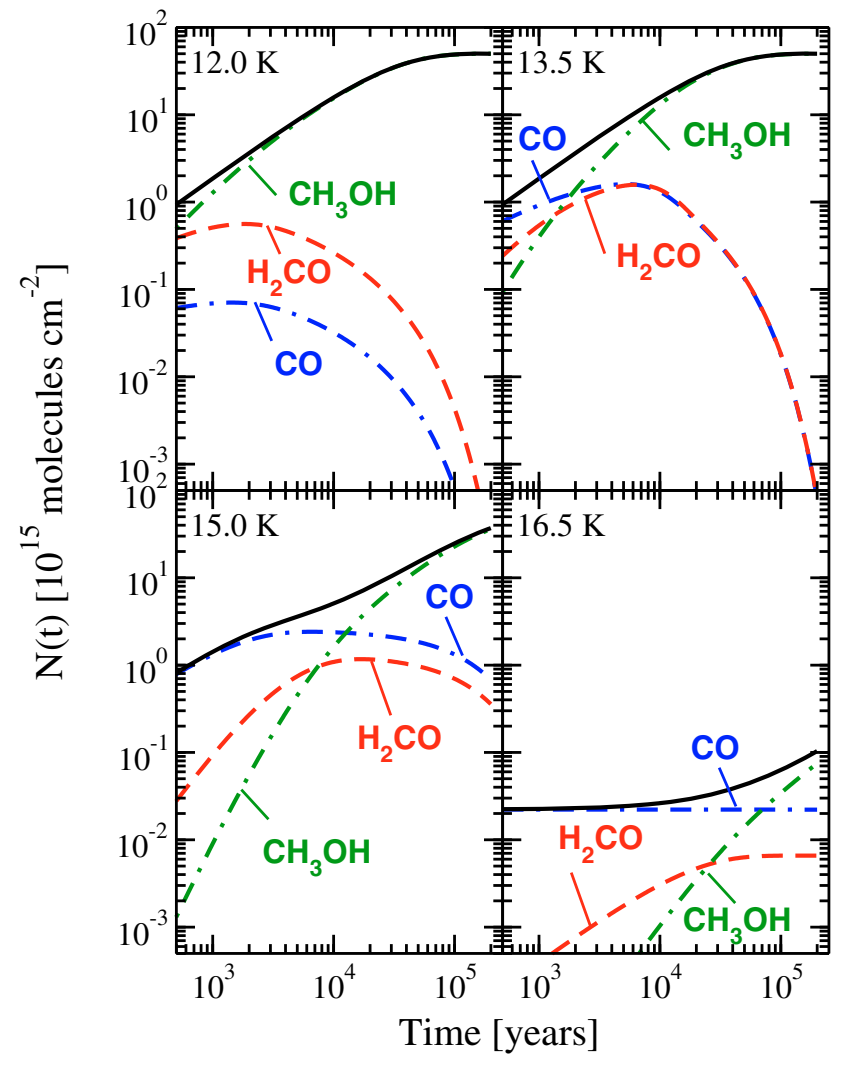

Fig. 8. Similar to Fig. 2 but using rate equations instead of Monte Carlo simulations.

\section{Comparison with other models and observations}

This section compares the results of our Monte Carlo simulations with different models and with observations of $\mathrm{H}_{2} \mathrm{CO}$ and $\mathrm{CH}_{3} \mathrm{OH}$ abundances. In particular, our results are compared with a similar model with similar input parameters using a standard rate equation technique (see, e.g., Ruffle \& Herbst 2000) and with different models of various degrees of chemical and astrophysical complexity that are reported in the literature. Finally, the simulations are compared with a steady-state model proposed by Charnley et al. (1997) that we have adjusted to take the changing $\mathrm{CO}$ gas-phase abundance into account.

\subsection{Comparison with rate equations}

Figure 8 plots the results for a rate equation model (see, e.g., Ruffle \& Herbst 2000) with the same chemical and physical processes as used in our Monte Carlo approach. Besides the difference in mathematical techniques, the rate equation method uses single hopping and desorption rates rather than rates that depend on the local structure. We expect the diffusion to be dominated by hopping between sites of the same type which results in a diffusion energy of $E_{\text {hop }}=8 E$ (see Eq. (4)) and the desorption dominated by strong binding sites (three horizontal neighbours), since diffusion will allow the particles to move to these sites where they remain attached. The competition between reactions with activation energy barriers and hopping and desorption is treated by dividing the rate coefficient for reaction by the total rate including diffusion and desorption, as discussed in detail by Herbst \& Millar (2008). The panels in Fig. 8 can be compared with those in Fig. 2, which are determined with the Monte Carlo approach.
In comparison with the Monte Carlo results, two trends become immediately apparent in the rate equation results: (1) there is a clear drop in the $\mathrm{CO}$ and $\mathrm{H}_{2} \mathrm{CO}$ abundances at late times and (2) the difference in the initial $\mathrm{CH}_{3} \mathrm{OH}$ formation $\left(<10^{3} \mathrm{yr}\right)$ increases with surface temperature. The drop in the surface abundance of $\mathrm{CO}$ and $\mathrm{H}_{2} \mathrm{CO}$ at late times is due to the mean field character of the rate equation technique. It treats all molecules of the same species in the same way, regardless of their position in the ice layers. CO ice that resides at the lower layers of the ice can in the standard implementation of the rate equation technique still react with impinging hydrogen atoms, whereas in reality this reaction will not proceed unless $\mathrm{H}$ atoms can penetrate into the porous ice. Figure 4 shows that indeed most of the $\mathrm{CO}$ and $\mathrm{H}_{2} \mathrm{CO}$ is buried deep into the ice. In the Monte Carlo simulations, the hydrogenation reactions will therefore be hampered by the deficiency of gas phase $\mathrm{CO}$ at late times whereas the rate equations continue hydrogenating the $\mathrm{CO}$ and $\mathrm{H}_{2} \mathrm{CO}$ that have been formed at early times. In general, the effect of a changing gas phase composition is limited to the top layers of the ice. For this reason, layering should be taken into account when modelling the grain surface chemistry. The three-phase model introduced by Hasegawa \& Herbst (1993) is a first attempt to implement this effect into a rate equation model.

The second effect is probably due to the difference in the treatment of diffusion and desorption between the two methods. The agreement in the total ice thickness indeed becomes less if lower desorption barriers are used. Due to the implementation of the competition for reaction in the rate equation approach, the choice of the diffusion barrier has very little effect on the final results. This can be understood by realising that faster diffusion will lead to more encounters between diffusers and the more stationary reacting species but that the residence time in the vicinity of the stationary reactant is reduced. The site dependent rates in the Monte Carlo code result in longer residence times at some sites and shorter residence times at other sites, favouring reactions, especially at higher temperatures, as first discovered for the formation of $\mathrm{H}_{2}$ (Cuppen \& Herbst 2005). In addition to the two effects, it can also been seen that with the rate equation approach, the ice cannot even develop to 1 monolayer at $16.5 \mathrm{~K}$, presumably because the $\mathrm{CO}$ growth mechanism of forming islands is not accounted for.

\subsection{Comparison with other surface models}

A variety of different models concerning the formation of formaldehyde and methanol via surface reactions from $\mathrm{CO}$ have been reported in the literature. Figure 9 (top) shows fractional methanol and formaldehyde abundances with respect to $n_{\mathrm{H}}$ as functions of the product of time and density $\left(n_{\mathrm{H}}\right)$ for a number of these models. This product is roughly proportional to the total fluence, the number of reaction species that reaches the grain surface, and can therefore serve as a measure to help compare models with different densities. The solid lines indicate the methanol and the dashed lines the formaldehyde abundances obtained in the present paper (Figs. 1, 2, and 7). Only the data at 8.0, 12.0 and $16.5 \mathrm{~K}$ are plotted since the 12.0 and $16.5 \mathrm{~K}$ data represent the extreme values and $8.0 \mathrm{~K}$ is closed to cold core conditions. The $n_{\mathrm{H}}=10^{4}$ and $10^{5} \mathrm{~cm}^{-3}$ data overlap nicely indicating that the formation rate of methanol and that of formaldehyde are directly dependent on the fluence and that the flux difference of one order of magnitude does not introduce additional scaling effects.

The symbols represent the fractional abundances of both species obtained from a selection of different studies. Open 


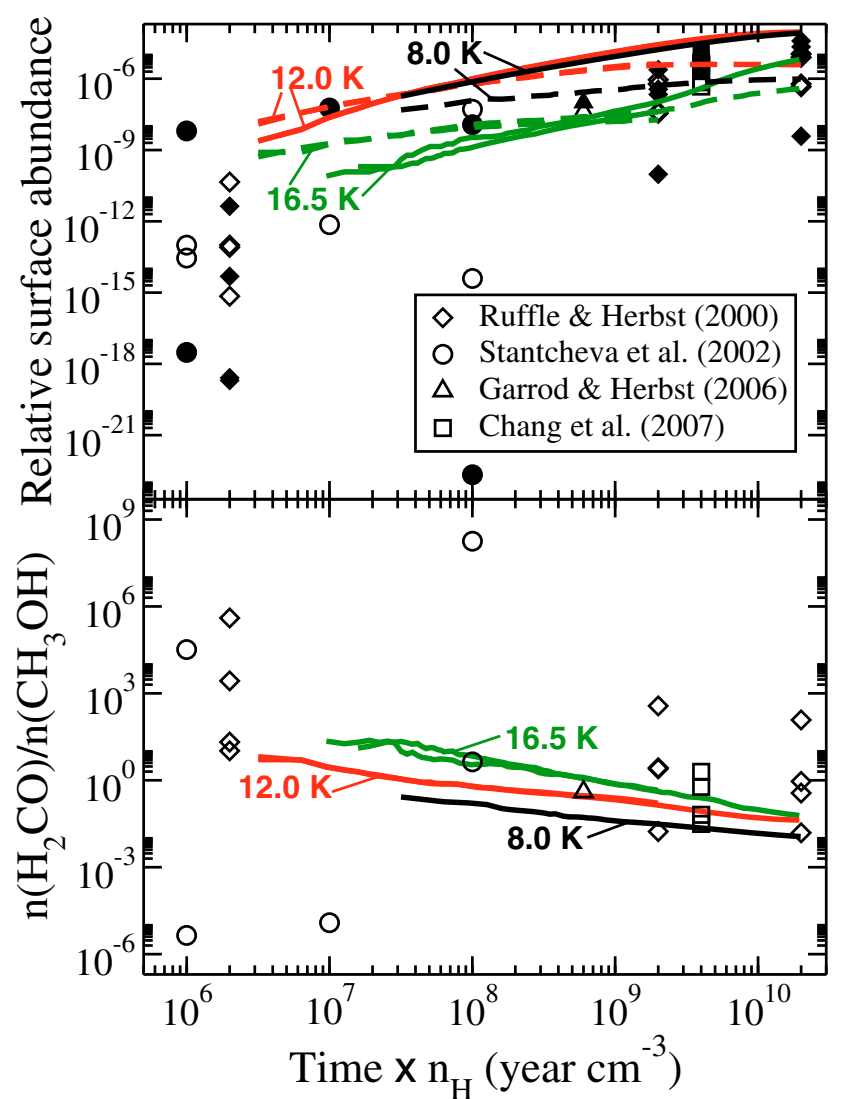

Fig. 9. Comparison of the present simulation data with values obtained by different models (see legend) as a function of time $\times$ density, which is a measure of fluence. The top panel displays the $\mathrm{H}_{2} \mathrm{CO}$ and $\mathrm{CH}_{3} \mathrm{OH}$ surface abundances relative to $n_{\mathrm{H}}$, the bottom panel $\mathrm{H}_{2} \mathrm{CO} / \mathrm{CH}_{3} \mathrm{OH}$ ratios. Lines represent the present model data for 8.0 (black), 12.0 (red) and $16.5 \mathrm{~K}$ (green) and $n_{\mathrm{H}}=10^{4} \mathrm{~cm}^{-3}$ and $10^{5} \mathrm{~cm}^{-3}$ (overlapping). $\mathrm{H}_{2} \mathrm{CO}$ is in dashed lines and $\mathrm{CH}_{3} \mathrm{OH}$ in solid lines. In the top panel, the open symbols represent $\mathrm{H}_{2} \mathrm{CO}$, the filled symbols $\mathrm{CH}_{3} \mathrm{OH}$.

symbols represent $\mathrm{H}_{2} \mathrm{CO}$ whereas filled symbols represent $\mathrm{CH}_{3} \mathrm{OH}$. Given the large differences in parameters, and assorted methods of calculation among the various studies, large variance in results can be expected. The diamonds show results by Ruffle $\&$ Herbst (2000), who used a large reaction network of both gas phase reactions and grain surface reactions. Both chemistries were treated using rate equations for four different scenarios defined by slow and fast diffusion rates combined with atomic and molecular initial conditions. The circles represent master equation results from Stantcheva et al. (2002). Here for a wide range of densities $\left(10^{3}, 10^{4}, 10^{5} \mathrm{~cm}^{-3}\right)$ the gas-grain chemistry for a limited set of surface reactions is obtained. Five additional reactions with respect to the surface network of the present paper were included, leading to the formation of $\mathrm{H}_{2} \mathrm{O}, \mathrm{CO}_{2}$ and $\mathrm{O}_{2}$. No gas phase chemistry was considered. The two triangles are obtained from Garrod et al. (2006), who followed both the gas and grain chemistry during the collapse and heat-up phase of hot cores using a rate equation approach. The points used here are in the early times of the collapse when the density is still close to the initial density. Again a full network was used, comparable to Ruffle \& Herbst (2000), but with intermediate diffusion rates. In all three models (Garrod et al. 2006; Ruffle \& Herbst 2000; Stantcheva et al. 2002) the barrier crossing of surface reactions with activation energy was treated simply by multiplying the meeting rates of reactive species by the probability of crossing the activation energy barrier. Unlike our rate equation approach (see above), surface reactions with barriers were not treated to be in competition with other processes like diffusion (Herbst $\&$ Millar 2008). This neglect magnifies the differences obtained between low and high diffusion rates. Furthermore, these three models do not capture the layered structure of the ice mantle but allow all species to react with each other, regardless of their position. This assumption can become a problem once multiple layers start to build up, as shown in the previous section.

The squares in Fig. 9 represent data from Chang et al. (2007) obtained by a similar Monte Carlo method to that used in the present paper (Chang et al. 2005), which includes both the layering effect as well as the competition of the reaction barriers. The surface chemistry is coupled to the gas phase chemistry and the surface chemistry network is very similar to one used by Stantcheva et al. (2002). The square symbols represent results for $n_{\mathrm{H}}=2 \times 10^{4} \mathrm{~cm}^{-3}$ and a surface temperature of 10 and $15 \mathrm{~K}$. The main difference between the method by Chang et al. (2007) and the present simulations is that our Monte Carlo algorithm is optimised to reproduce laboratory experiments and it includes important features of the $\mathrm{CO}+\mathrm{H}$ system that were revealed through this optimisation.

In general, Fig. 9 shows a large spread which reflects the different levels of complexity among the different methods. Most of the obtained abundances of $\mathrm{H}_{2} \mathrm{CO}$ and $\mathrm{CH}_{3} \mathrm{OH}$ lie between our 12.0 and $16.5 \mathrm{~K}$ results and follow roughly the same trend that $\mathrm{H}_{2} \mathrm{CO}$ dominates at early times and $\mathrm{CH}_{3} \mathrm{OH}$ at late times. It appears that the slow diffusion results underestimate the formation of both molecules and the $\mathrm{CH}_{3} \mathrm{OH} / \mathrm{H}_{2} \mathrm{CO}$ ratio, as compared to our model that is parameterized by experiments. Our $8.0 \mathrm{~K}$ data lie on the high end of the results, probably for two reasons. Our $n(\mathrm{CO})$ is relatively high throughout the entire simulation, although it should be comparable to the intermediate abundance of Stantcheva et al. (2002), and our limited network might overproduce $\mathrm{H}_{2} \mathrm{CO}$ and $\mathrm{CH}_{3} \mathrm{OH}$ instead of forming $\mathrm{H}_{2} \mathrm{O}$ and $\mathrm{CO}_{2}$ for instance. Our simulations are however geared towards conditions where most of the atomic oxygen is locked up in $\mathrm{CO}$, and $\mathrm{H}$ and $\mathrm{CO}$ are indeed the most important reactants on the surface.

The bottom panel of Fig. 9 shows the $\mathrm{H}_{2} \mathrm{CO} / \mathrm{CH}_{3} \mathrm{OH}$ ratio for the low temperature models $(<20 \mathrm{~K})$ presented in the top panel. It is immediately evident from this plot that there is a spread in this quantity for the different models, even within the same paper. The difference in the $\mathrm{H}_{2} \mathrm{CO} / \mathrm{CH}_{3} \mathrm{OH}$ ratio for our $8.0,12.0$ and $16.5 \mathrm{~K}$ is much smaller compared with the spread found in other models. This spread is due to different assumptions in the modelling method and differences in methodology. In a few instances, the spread is due to different physical conditions such as temperature (as in our data) and density. In general, the largest differences with our results come from models with a low diffusion rate that do not consider the competition between reaction and diffusion.

\subsection{Comparison with analytical model}

Charnley et al. (1997) derived an analytical steady-state rate equation approach to predict the $\mathrm{CO} / \mathrm{CH}_{3} \mathrm{OH}$ and $\mathrm{H}_{2} \mathrm{CO} / \mathrm{CH}_{3} \mathrm{OH}$ surface abundance ratios as functions of $\alpha_{\mathrm{H}}$, the relative H-toCO flux ratio, and $\phi_{\mathrm{H}}=P_{\mathrm{CO}} / P_{\mathrm{H}_{2} \mathrm{CO}}$, the ratio of the probabilities for single $\mathrm{CO}$ and $\mathrm{H}_{2} \mathrm{CO}$ molecules to react with an $\mathrm{H}$ atom; i.e., the ratio of the rate coefficients. The exact derivation of these expressions is given in Appendix A. Each value for $\alpha_{\mathrm{H}}$ and $\phi_{\mathrm{H}}$ results in a unique combination of both abundance ratios. When Charnley et al. (1997) was published, $\phi_{\mathrm{H}}$ was unknown. Now, we can use Table 1 to obtain this quantity for different 


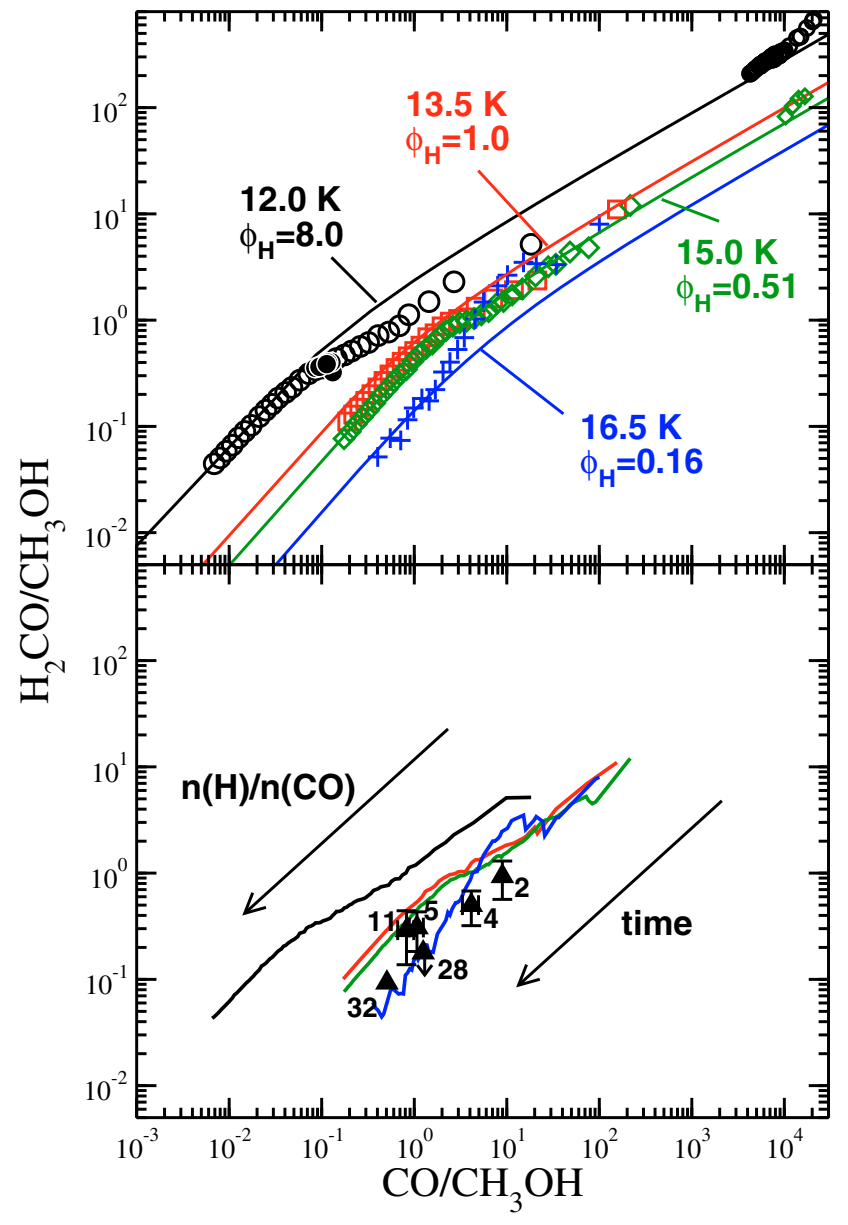

Fig. 10. $\mathrm{CO} / \mathrm{CH}_{3} \mathrm{OH}$ versus $\mathrm{H}_{2} \mathrm{CO} / \mathrm{CH}_{3} \mathrm{OH}$ ice abundance. The top panel compares results as obtained by the Monte Carlo simulations (open symbols) and Eqs. (A.6)-(A.8) (solid lines). The filled circles represent a simulation at $12.0 \mathrm{~K}$ that includes an $\mathrm{O}$-atom flux. The bottom panel indicates the Monte Carlo results by solid lines. The triangles indicate ratios from ice observations where the numbers refer to the methanol content in the ice with respect to $\mathrm{H}_{2} \mathrm{O}$ (see text). The quantity $\phi_{\mathrm{H}}$ represents the ratio between the $\mathrm{H}+\mathrm{CO}$ and $\mathrm{H}+\mathrm{H}_{2} \mathrm{CO}$ reaction rates.

temperatures, so as to compare this steady state rate equation approach with the more realistic Monte Carlo simulations.

The top panel of Fig. 10 plots the $n(\mathrm{CO}) / n\left(\mathrm{CH}_{3} \mathrm{OH}\right)$ abundance ratio versus the $n\left(\mathrm{H}_{2} \mathrm{CO}\right) / n\left(\mathrm{CH}_{3} \mathrm{OH}\right)$ abundance for the Monte Carlo simulations (open symbols except for $16.5 \mathrm{~K}$ ) and for the steady-state model (lines). For each temperature, $\phi_{\mathrm{H}}$ is indicated as obtained from Table 1. The Monte Carlo curves follow the abundance ratios in time; i.e., they start from a relatively high CO gas-phase abundance which is partially converted into formaldehyde and methanol, so that the general direction is right to left. Likewise, the general direction is from top to bottom since formaldehyde is generally converted into methanol. The steady-state model by Charnley et al. (1997) plots curves for varying $\alpha_{\mathrm{H}}$. Since $\alpha_{\mathrm{H}}$ increases gradually during the course of our simulations, both approaches can be compared in a relative straightforward way although the simulations have also other sources of time dependence. The time it takes for the top layer of the grain mantle to reach steady state is short as compared to the change in $\alpha_{\mathrm{H}}$. Figure 10 (top) includes the steady-state model lines for values of $\phi_{\mathrm{H}}$ that correspond to the values in the simulations. We would like to emphasise that the lines by Charnley et al. (1997) represent $\theta_{\mathrm{CO}} / \theta_{\mathrm{CH}_{3} \mathrm{OH}}$ and $\theta_{\mathrm{H}_{2} \mathrm{CO}} / \theta_{\mathrm{CH}_{3} \mathrm{OH}}$, where $\theta_{X}$ indicates the steady-state coverage of species $\mathrm{X}$ in the top layer, whereas the abundances in the Monte Carlo simulations are for the entire grain mantle. At first sight, very good agreement is obtained between the simulation results and the analytical model, especially considering the requirement for steady state in the latter, which is not fulfilled in the Monte Carlo simulations. However, it must be remembered that in the absence of a third dimension to the plot, $\alpha_{\mathrm{H}}$ is a hidden parameter, and the agreement for $\alpha_{\mathrm{H}}$ between the two methods for the same points on the figure is not good. Indeed, the same results in Fig. 10 are obtained for a 5-20 times lower H/CO flux in the steady-state model as compared with the simulations. In the simulations, a significant portion of the $\mathrm{H}$ atoms are "lost" to $\mathrm{H}_{2}$ formation and desorption. Both processes are not included in the model by Charnley et al. (1997).

The smaller symbols in the right top corner are the result of simulations with a different starting $\mathrm{H}$ abundance, chosen such that the flux of $\mathrm{CO}$ molecules is 10 times higher than the $\mathrm{H}$ atom flux, e.g., $\alpha_{H}$ is 0.1 at the start of the simulation. The absolute abundances of $\mathrm{H}$ and $\mathrm{CO}$ have little influence on the obtained ratios. These independent simulations continue nicely on the analytical curve. As Keane (2001) shows, the introduction of more competing hydrogenation reactions leads to different curves. Section 5 addresses this point in more detail.

One purpose behind a plot like Fig. 10 is to visualise whether $\mathrm{H}$ atoms are more likely to react with $\mathrm{CO}$ or $\mathrm{H}_{2} \mathrm{CO}$. The laboratory results indicate that for low temperature $(12.0 \mathrm{~K}) \mathrm{CO}$ $+\mathrm{H}$ is dominant whereas $\mathrm{H}_{2} \mathrm{CO}$ hydrogenation becomes the preferred channel for higher temperatures $(16.5 \mathrm{~K})$. The plot shows that, even though the $\alpha_{\mathrm{H}}$ agreement is not very good, the agreement for $\phi_{\mathrm{H}}$ is very nice. The curves in Fig. 10 (top) are for one value of $\phi_{\mathrm{H}}$ and varying $\alpha_{\mathrm{H}}$, which can be compared with the simulations at a single temperature. The steady-state model and Monte Carlo simulation results for the same value of $\phi_{\mathrm{H}}$ trace the same unique lines in the $n(\mathrm{CO}) / n\left(\mathrm{CH}_{3} \mathrm{OH}\right)$ versus $n\left(\mathrm{H}_{2} \mathrm{CO}\right) / n\left(\mathrm{CH}_{3} \mathrm{OH}\right)$ plot. Since $\phi_{\mathrm{H}}$ decreases with temperature, plotting observational $\mathrm{H}_{2} \mathrm{CO} / \mathrm{CH}_{3} \mathrm{OH}$ versus $\mathrm{CO} / \mathrm{CH}_{3} \mathrm{OH}$ ratios could give a good temperature and evolutionary indication between sources.

The main conclusions that can be drawn from these comparisons are that the surface chemistry of the top layer can at each point in time be very well approximated by quasi-steady state conditions, since the time to reach a quasi-steady state is smaller than the change in flux, and that the majority of the hydrogen atoms do not react but leave the surface by desorption. This means that the conversion rate of $\mathrm{CO}$ and $\mathrm{H}_{2} \mathrm{CO}$ into more saturated species is overestimated by the model of Charnley et al. (1997). Table 3 lists the steady-state conversion fractions of CO into $\mathrm{H}_{2} \mathrm{CO}$ and $\mathrm{CH}_{3} \mathrm{OH}$ as a function of temperature and $\mathrm{H} / \mathrm{CO}$ gas phase abundance ratio obtained from the Monte Carlo simulations. The calculated fractions include the effect of desorption of atomic hydrogen and the competition of the $\mathrm{CO}$ hydrogenation reactions with the formation of $\mathrm{H}_{2}$, which is not included in the analytical model.

These conversion fractions clearly show that $\mathrm{CO}$ is very efficiently converted into $\mathrm{H}_{2} \mathrm{CO}$ and $\mathrm{CH}_{3} \mathrm{OH}$. Naturally, the exact numbers depend on many assumptions regarding for instance the values of $E, \xi$ and the reaction barriers. The parameter $E$ is central in determining the desorption temperature of the species and an increase in $E$ will therefore result in an appreciable $\mathrm{H}$-atom abundance at higher temperature increasing the hydrogenation regime with a few degrees. The diffusion parameter $\xi$, on the other hand, will have a stronger effect at low temperature. 
Table 3. Conversion fraction of $\mathrm{CO}$ into $\mathrm{H}_{2} \mathrm{CO}$ and $\mathrm{CH}_{3} \mathrm{OH}$ as a function of $T$ and $\mathrm{H} / \mathrm{CO}$.

\begin{tabular}{rllll}
\hline \hline$\frac{n(\mathrm{H})}{n(\mathrm{CO})}$ & \multicolumn{4}{c}{ Temperature $(\mathrm{K})$} \\
& 12.0 & 13.5 & 15.0 & 16.5 \\
\hline $\mathrm{H}_{2} \mathrm{CO}$ & & & & \\
0.50 & $5.4 \times 10^{-1}$ & $2.4 \times 10^{-1}$ & $1.4 \times 10^{-1}$ & $3.0 \times 10^{-2}$ \\
0.75 & $3.7 \times 10^{-1}$ & $2.3 \times 10^{-2}$ & $1.7 \times 10^{-1}$ & $3.0 \times 10^{-2}$ \\
1.00 & $1.8 \times 10^{-1}$ & $2.1 \times 10^{-1}$ & $1.9 \times 10^{-1}$ & $4.0 \times 10^{-2}$ \\
2.00 & $6.8 \times 10^{-3}$ & $4.3 \times 10^{-2}$ & $1.6 \times 10^{-1}$ & \\
5.00 & $1.0 \times 10^{-5}$ & $1 \times 10^{-3}$ & $2.1 \times 10^{-2}$ \\
\hline $\mathrm{CH}_{3} \mathrm{OH}$ & \multicolumn{5}{|c}{} \\
0.50 & $2.1 \times 10^{-1}$ & $1.8 \times 10^{-1}$ & $5.2 \times 10^{-2}$ & $8.5 \times 10^{-1}$ \\
0.75 & $5.4 \times 10^{-1}$ & $3.1 \times 10^{-1}$ & $1.1 \times 10^{-1}$ & $7.5 \times 10^{-1}$ \\
1.00 & $9.9 \times 10^{-1}$ & $3.3 \times 10^{-1}$ & $1.1 \times 10^{-1}$ & $7.1 \times 10^{-1}$ \\
2.00 & $1.0 \times 10^{0}$ & $8.6 \times 10^{-1}$ & $4.4 \times 10^{-1}$ & \\
5.00 & $1.0 \times 10^{0}$ & $1.0 \times 10^{0}$ & $1.0 \times 10^{0}$ & \\
\hline
\end{tabular}

Finally, a change in the reaction barriers will lead to a slightly different $\mathrm{H}_{2} \mathrm{CO} / \mathrm{CH}_{3} \mathrm{OH}$ ratio.

\subsection{Comparison with observations}

A comparison between the simulation results presented in this paper and observations is most straightforward with IR ice data. As long as the ice is not processed too severely, either by UV photons, which can break down formaldehyde and methanol, or by heating, which can sublimate $\mathrm{CO}$, the IR data represents the most direct comparison with our simulations (see Sect. 5 below). Ideal conditions are most likely found in cold dense cores or the outer cold envelopes of YSO's. Since it is difficult to use absolute column densities for the comparison, the same ratios are used as in Fig. 10. CO is usually present on grains in different mixtures: pure $\mathrm{CO}$, polar $\mathrm{CO}$ and $\mathrm{CO}$ mixed with $\mathrm{CO}_{2}$ (Pontoppidan et al. 2008). Laboratory spectra of $\mathrm{CO}$ mixed with either $\mathrm{H}_{2} \mathrm{O}$ or $\mathrm{CH}_{3} \mathrm{OH}$ show similar changes in the $4.7 \mu \mathrm{m}$ CO feature, broadening and redshifting (Bisschop 2007; Bottinelli et al. in prep; Bouwman et al. 2007). The polar CO component at $2139 \mathrm{~cm}^{-1}$, normally ascribed to $\mathrm{CO}$ in a water-rich ice, can therefore also be due to a methanol-rich mixture. A $\mathrm{CO}: \mathrm{CH}_{3} \mathrm{OH}=1: 1$ mixture is already sufficient to shift the band to the observed range. Thus, to obtain the observed $\mathrm{CO} / \mathrm{CH}_{3} \mathrm{OH}$ ratio for comparison with our models, we use both the pure $\mathrm{CO}$ component and the polar $\mathrm{CO}$ component to account for the maximum amount of $\mathrm{CO}$ mixed with the formed $\mathrm{CH}_{3} \mathrm{OH}$ ice. The triangles in the bottom panel of Fig. 10 represent ratios obtained from ISO data for the YSO's AFGL 989, AFGL 2136, W33A, AFGL 7009S, and NGC 7538 IRS9 (Gibb et al. 2004) and VLT-ISAAC data for the Class 0 source Serpens SMM 4 (Pontoppidan et al. 2004). Arrows indicate upper limits. As with the earlier data, Spitzer spectra of sources near SMM4 by Boogert et al. (2008) resulted only in upper limits for $\mathrm{H}_{2} \mathrm{CO}$. They found formaldehyde to contribute perhaps $10-35 \%$ of their $\mathrm{C} 1$ component, which cannot be assigned to a single species. Gibb et al. (2004) used a feature equivalent to the $\mathrm{C} 1$ component to obtain their reported $\mathrm{H}_{2} \mathrm{CO}$ abundances. Both the $\mathrm{H}_{2} \mathrm{CO}$ abundances by Gibb et al. (2004) and the $\mathrm{H}_{2} \mathrm{CO}$ part of the $\mathrm{C} 1$ components by Boogert et al. (2008) vary minimally with respect to water ice and are typically $6 \%$. The range in $\mathrm{H}_{2} \mathrm{CO} / \mathrm{CH}_{3} \mathrm{OH}$ abundances is therefore mainly due to methanol. The abundance ratios for the six sources nicely overlap with the simulation data (solid lines). The good agreement with the $\mathrm{CO} / \mathrm{CH}_{3} \mathrm{OH}$ ratio could however be deceiving if part of the $\mathrm{CO}$ ice has already desorbed.
Solid methanol abundances are found to vary substantially with respect to water ice, ranging from upper limits of a few percent to more than 30\% (Boogert et al. 2008; Dartois et al. 1999; Pontoppidan et al. 2003). In Fig. 10, these percentages are indicated for the six sources compared here, spanning a range of more than an order of magnitude, assuming that, as discussed above, $\mathrm{H}_{2} \mathrm{CO}$ ice does not vary much in abundance. A reason for this large range could lie in the differing evolutionary stages of the sources. If most of the water ice is formed first before the catastrophic freeze-out of $\mathrm{CO}$, from which methanol is formed, the methanol over water ratio will increase in time. The temporal evolution of the simulated abundance ratios proceeds from the top-right corner to the bottom-left corner of the figure, and the increase in methanol abundances for the six sources appears to follow this trend, suggesting that indeed the large spread in methanol observations can simply be due to a difference in evolutionary stage of the outer envelope. Unfortunately, solid $\mathrm{H}_{2} \mathrm{CO}$ has only been detected in a handful of sources and the same holds for clear upper limits for this molecule.

An alternative observational test could be to perform $\mathrm{CO}$, $\mathrm{H}_{2} \mathrm{CO}$, and $\mathrm{CH}_{3} \mathrm{OH}$ gas phase observations in very cold and dense cores, where all three species are frozen-out onto the grains. Since most molecules have similar non-thermal desorption rates (Öberg et al. 2009a,b), one would expect the trace amounts in the gas phase to be representative of the ice layer composition (Öberg et al. 2009c). The problem with this technique is that not all observed gas-phase $\mathrm{CO}$ may result from $\mathrm{CO}$ ice evaporation and that gas-phase reactions can contribute to $\mathrm{H}_{2} \mathrm{CO}$ as well. As shown in Fig. 12 of Fuchs et al. (2009), the current model can reproduce the observed $\mathrm{H}_{2} \mathrm{CO} / \mathrm{CH}_{3} \mathrm{OH}$ ratios in high-mass hot cores where the majority of the observed gasphase molecules are likely evaporated ice species.

By ignoring the formation of water ice, our model predicts that $\mathrm{CH}_{3} \mathrm{OH}$ is mainly present on the grain mantles in the pure form or mixed with $\mathrm{CO}$, and that it is not in a water-rich phase. Unfortunately, the ice composition has very little effect on the $9.75 \mu \mathrm{m}$ band profile of $\mathrm{CH}_{3} \mathrm{OH}$, which is usually used to determine its abundance, neither in peak shape nor position. The feature only becomes red-shifted when water ice is dominant, $>90 \%$ (Bottinelli et al. in prep.; Skinner et al. 1992). Similarly, the $3.54 \mu \mathrm{m} \mathrm{CH}_{3} \mathrm{OH}$ feature can be used to constrain the $\mathrm{CH}_{3} \mathrm{OH}$ ice environment (Dartois et al. 1999; Pontoppidan et al. 2003; Thi et al. 2006). All of these studies generally conclude that at least a fraction of the $\mathrm{CH}_{3} \mathrm{OH}$ ice is in a water-poor, $\mathrm{CH}_{3} \mathrm{OH}$-rich environment but additional laboratory data on $\mathrm{CH}_{3} \mathrm{OH}$ mixtures with $\mathrm{CO}$ are needed to quantify this.

\section{Impact of competing reactions}

The Monte Carlo simulations reported in the previous sections all involve hydrogenation of pure CO ice. The reason for this is two fold. First, one aim of this study is to model CO freeze-out in the centre of cold cloud cores (Pontoppidan 2006; Pontoppidan et al. 2008) where most of the gas is in molecular form and $\mathrm{H}_{2}$ and $\mathrm{CO}$ are the dominant species. In these centres, most of the elemental oxygen is in the form of $\mathrm{CO}$ or frozen out into grains in form of $\mathrm{H}_{2} \mathrm{O}$.

To study the effect of competing reactions, however, simulations that include oxygen atoms have been performed as well. These simulations use a reaction network that is similar to that reported by Chang et al. (2007), leading to the formation of $\mathrm{O}_{2}$, $\mathrm{H}_{2} \mathrm{O}$, and $\mathrm{CO}_{2}$. In addition, $\mathrm{H}_{2} \mathrm{CO}$ and $\mathrm{H}_{3} \mathrm{CO}$ can be destroyed by reaction with $\mathrm{OH}$, leading to the formation of water (see Table 4). All new species are assumed to bind very strongly and 
Table 4. Surface reactions in the $\mathrm{H}, \mathrm{O}$ and $\mathrm{CO}$ system.

\begin{tabular}{llll}
\hline \hline Reactants & & Products & $E_{\mathrm{a}}(\mathrm{K})$ \\
\hline $\mathrm{H}+\mathrm{H}$ & $\rightarrow$ & $\mathrm{H}_{2}$ & \\
$\mathrm{H}+\mathrm{O}$ & $\rightarrow$ & $\mathrm{OH}$ & \\
$\mathrm{H}+\mathrm{OH}$ & $\rightarrow$ & $\mathrm{H}_{2} \mathrm{O}$ & \\
$\mathrm{H}+\mathrm{CO}$ & $\rightarrow$ & $\mathrm{HCO}$ & Table 1 \\
$\mathrm{H}+\mathrm{HCO}$ & $\rightarrow$ & $\mathrm{H}_{2} \mathrm{CO}$ & \\
$\mathrm{H}+\mathrm{H}_{2} \mathrm{CO}$ & $\rightarrow$ & $\mathrm{H}_{3} \mathrm{CO}$ & Table 1 \\
$\mathrm{H}+\mathrm{H}_{3} \mathrm{CO}$ & $\rightarrow$ & $\mathrm{CH}_{3} \mathrm{OH}$ & \\
$\mathrm{O}+\mathrm{O}$ & $\rightarrow$ & $\mathrm{O}_{2}$ & \\
$\mathrm{O}+\mathrm{OH}$ & $\rightarrow$ & $\mathrm{O}_{2}+\mathrm{H}$ & \\
$\mathrm{CO}+\mathrm{OH}$ & $\rightarrow$ & $\mathrm{CO}_{2}+\mathrm{H}$ & 176 \\
$\mathrm{OH}+\mathrm{H}_{2} \mathrm{CO}$ & $\rightarrow$ & $\mathrm{HCO}_{2} \mathrm{H}$ & \\
$\mathrm{OH}+\mathrm{H}_{3} \mathrm{CO}$ & $\rightarrow$ & $\mathrm{H}_{2} \mathrm{CO}+\mathrm{H}_{2} \mathrm{O}$ & \\
\hline
\end{tabular}

have only minimal diffusion. Eley-Rideal reactions are again allowed. The gas-phase abundances of $\mathrm{CO}$ and $\mathrm{O}$ are both assumed to be $5 \times 10^{-5} n(\mathrm{H})$. Figure 10 contains results for the simulation at $12.0 \mathrm{~K}$ using filled circles. From this figure, two things are immediately clear: the time dependence of the $\mathrm{CO} / \mathrm{CH}_{3} \mathrm{OH}$ and $\mathrm{H}_{2} \mathrm{CO} / \mathrm{CH}_{3} \mathrm{OH}$ ratios is minimal in the simulation and the filled circles overlap nicely with the analogous simulations that do not include the extra reactions. Keane (2001) presents a similar graph obtained with a full gas-grain network using macroscopic Monte Carlo simulations. Their curves obtained for the full network are less steep than for the analytical expressions that are based on a limited network, since a considerable fraction of the hydrogen atoms reacts with other grain species. This is in contrast with our simulations that include $\mathrm{H}_{2} \mathrm{O}$ and $\mathrm{CO}_{2}$ as competing mechanisms. The origin of this discrepancy is unclear.

Another type of competing reaction would be the destruction of methanol by photodissociation. The photofragments could then react to synthesise more complex molecules. In dense cloud conditions, photodissociation mainly occurs via cosmic ray induced photons, with a typical flux of $5 \times 10^{3}$ photons $\mathrm{cm}^{-2} \mathrm{~s}^{-1}$ (Cecchi-Pestellini \& Aiello 1992). Using a photodissociation cross section of $1.6 \times 10^{-18} \mathrm{~cm}^{2}$ (Gerakines et al. 1996; Öberg et al. 2009d), $5 \%$ of the methanol molecules has been photodissociated in $2 \times 10^{5}$ years. Most of these molecules are dissociated to simpler species like $\mathrm{CO}, \mathrm{HCO}, \mathrm{CH}_{3}, \mathrm{CH}_{3} \mathrm{O}$, and $\mathrm{H}_{2} \mathrm{CO}$ and can be hydrogenated to methanol again. Gas-phase $\mathrm{H}$ atoms can hydrogenate the radicals in top layers of the ice, whereas $\mathrm{H}$ atoms that are produced through photodissociation can react with the fragments deep in the ice. We therefore expect only a minor change in the grain abundances due to photodissociation as long as the grains remain cold. Higher temperatures allow the radicals to diffuse rapidly enough to form large molecules such as methyl formate and dimethyl ether (Garrod et al. 2008; Öberg et al. 2009d).

\section{Conclusions}

The surface formation of $\mathrm{CH}_{3} \mathrm{OH}$ and $\mathrm{H}_{2} \mathrm{CO}$ from precursor $\mathrm{CO}$ has been simulated using the continuous-time, random-walk Monte Carlo method. The formation of both species was found to be very efficient under certain conditions and to depend mainly on grain temperature and the gas phase abundance ratio of $\mathrm{H}$ and $\mathrm{CO}$. During the freeze-out of $\mathrm{CO}$ onto the grain, this ratio changes, favouring the more complete hydrogenation of $\mathrm{CO}$ to $\mathrm{CH}_{3} \mathrm{OH}$. The more unsaturated species remain locked in the lower layers of the ice mantle. Due to the layering of the ice, changes in the gas phase abundance can only affect the top layers of the grain, which is important to take into account when modelling grain surface chemistry. The detailed Monte Carlo method used can be compared with a variety of other approaches. Of these, perhaps the most successful is a quasi-steady-state rate equation approach (Charnley et al. 1997) that focuses on the outermost layer of the grain only.

The model results can be compared with observations through plots of the $\mathrm{CO} / \mathrm{CH}_{3} \mathrm{OH}$ and $\mathrm{H}_{2} \mathrm{CO} / \mathrm{CH}_{3} \mathrm{OH}$ abundance ratios. A very good agreement is obtained for the outer envelopes of a number of YSO's, with temperatures in the range $12.0-16.5 \mathrm{~K}$. Moreover, the comparison allows us to trace the temporal evolution between different sources. Our results suggest that the difference in $\mathrm{CH}_{3} \mathrm{OH}$ abundances with respect to water are mostly due to differences in temporal evolution where the younger sources have not yet had sufficient time to build up much methanol.

Acknowledgements. H. C. is supported by the Netherlands Organization for Scientific Research (NWO) and the Leiden Observatory. E. H. thanks the National Science Foundation (US) and NASA for support of his research programs in astrochemistry and astrobiology. We would like to thank Lars Kristensen, Karin Öberg, and Harold Linnartz for stimulating discussions.

\section{Appendix A: CO hydrogenation in steady state conditions}

This appendix presents a derivation of the steady state model proposed by Charnley et al. (1997). When the flux of hydrogen atoms to the surface is lower than the flux of $\mathrm{CO}$ molecules, the assumption can be made that every hydrogenation atom either reacts with $\mathrm{CO}$ or with $\mathrm{H}_{2} \mathrm{CO}$. The probabilities of reaction are denoted by $\chi_{\mathrm{CO}}$ and $\chi_{\mathrm{H}_{2} \mathrm{CO}}$, respectively. They are determined by the likelihood of barrier crossing once an $\mathrm{H}$ atom is in the vicinity of the $\mathrm{CO}$ or $\mathrm{H}_{2} \mathrm{CO}, P_{\mathrm{CO}}$ and $P_{\mathrm{H}_{2} \mathrm{CO}}$, and the fractional coverage of these species over the outermost surface layer, $\theta_{\mathrm{CO}}$ and $\theta_{\mathrm{H}_{2} \mathrm{CO}}$ according to the equations

$$
\chi_{\mathrm{CO}}=\frac{P_{\mathrm{CO}} \theta_{\mathrm{CO}}}{P_{\mathrm{CO}} \theta_{\mathrm{CO}}+P_{\mathrm{H}_{2} \mathrm{CO}} \theta_{\mathrm{H}_{2} \mathrm{CO}}}
$$

and

$\chi_{\mathrm{H}_{2} \mathrm{CO}}=\frac{P_{\mathrm{H}_{2} \mathrm{CO}} \theta_{\mathrm{H}_{2} \mathrm{CO}}}{P_{\mathrm{CO}} \theta_{\mathrm{CO}}+P_{\mathrm{H}_{2} \mathrm{CO}} \theta_{\mathrm{H}_{2} \mathrm{CO}}}$.

The change in $\mathrm{CO}$ coverage with time is then

$\frac{\mathrm{d} \theta_{\mathrm{CO}}}{\mathrm{d} t}=f_{\mathrm{CO}}\left(1-\theta_{\mathrm{CO}}\right)-2 f_{\mathrm{H}} \chi_{\mathrm{CO}}$

Here the first term accounts for the increase by the incoming $\mathrm{CO}$ flux, $f_{\mathrm{CO}}$ where the $-\theta_{\mathrm{CO}}$ accounts for covering of surface $\mathrm{CO}$ by new $\mathrm{CO}$ and the second, last term is due to reaction of $\mathrm{CO}$ with $\mathrm{H}$. The factor two accounts for the two successive hydrogenation reactions to form $\mathrm{H}_{2} \mathrm{CO}$. In a similar fashion, rate equations for the surface coverage of $\mathrm{H}_{2} \mathrm{CO}$ and $\mathrm{CH}_{3} \mathrm{OH}$ can be determined to be

$\frac{\mathrm{d} \theta_{\mathrm{H}_{2} \mathrm{CO}}}{\mathrm{d} t}=2 f_{\mathrm{H}}\left(\chi_{\mathrm{CO}}-\chi_{\mathrm{H}_{2} \mathrm{CO}}\right)-f_{\mathrm{CO}} \theta_{\mathrm{H}_{2} \mathrm{CO}}$

and

$\frac{\mathrm{d} \theta_{\mathrm{CH}_{3} \mathrm{OH}}}{\mathrm{d} t}=2 f_{\mathrm{H}} \chi_{\mathrm{H}_{2} \mathrm{CO}}-f_{\mathrm{CO}} \theta_{\mathrm{CH}_{3} \mathrm{OH}}$.

From Eqs. (A.4) and (A.5), $\theta_{\mathrm{H}_{2} \mathrm{CO}} / \theta_{\mathrm{CH}_{3} \mathrm{OH}}$ is given by

$\frac{\theta_{\mathrm{H}_{2} \mathrm{CO}}}{\theta_{\mathrm{CH}_{3} \mathrm{OH}}}=\phi_{\mathrm{H}} \frac{\theta_{\mathrm{CO}}}{\theta_{\mathrm{H}_{2} \mathrm{CO}}}-1$ 
with

$\phi_{\mathrm{H}} \equiv \frac{P_{\mathrm{CO}}}{P_{\mathrm{H}_{2} \mathrm{CO}}}$

and furthermore

$\frac{\theta_{\mathrm{CO}}}{\theta_{\mathrm{CH}_{3} \mathrm{OH}}}=\frac{\theta_{\mathrm{H}_{2} \mathrm{CO}}}{\theta_{\mathrm{CH}_{3} \mathrm{OH}}} \frac{\theta_{\mathrm{CO}}}{\theta_{\mathrm{H}_{2} \mathrm{CO}}}$.

From Eqs. (A.3) and (A.4) and using Eqs. (A.1), (A.2), we obtain that

$$
\begin{aligned}
& \frac{\theta_{\mathrm{CO}}}{\theta_{\mathrm{H}_{2} \mathrm{CO}}}= \\
& \frac{1+2 \phi_{\mathrm{H}} / \alpha_{\mathrm{H}}-\phi_{\mathrm{H}}+\sqrt{\left(1+2 \phi_{\mathrm{H}} / \alpha_{\mathrm{H}}-\phi_{\mathrm{H}}\right)^{2}+8 \phi_{\mathrm{H}} / \alpha_{\mathrm{H}}}}{2 \phi_{\mathrm{H}}}
\end{aligned}
$$

where

$\alpha_{\mathrm{H}} \equiv \frac{f_{\mathrm{H}}}{f_{\mathrm{CO}}}$.

\section{References}

Al-Halabi, A., \& van Dishoeck, E. F. 2007, MNRAS, 382, 1648 Allamandola, L. J., Sandford, S. A., Tielens, A. G. G. M., et al. 1992, ApJ, 399, 134

Bergin, E. A., Alves, J., Huard, T., et al. 2002, ApJ, 570, L101

Bisschop, S. E. 2007, Ph.D. Thesis, Leiden Observatory, Leiden University

Bisschop, S. E., Jørgensen, J. K., van Dishoeck, E. F., et al. 2007, A\&A, 465, 913

Boogert, A. C. A., Pontoppidan, K. M., Knez, C., et al. 2008, ApJ, 678, 985 Bouwman, J., Ludwig, W., Awad, Z., et al. 2007, A\&A, 476, 995

Caselli, P., Walmsley, C. M., Tafalla, M., Dore, L., \& Myers, P. C. 1999, ApJ, 523, L165

Cecchi-Pestellini, C., \& Aiello, S. 1992, MNRAS, 258, 125

Chang, Q., Cuppen, H. M., \& Herbst, E. 2005, A\&A, 434, 599

Chang, Q., Cuppen, H. M., \& Herbst, E. 2007, A\&A, 469, 973

Charnley, S. B., Tielens, A. G. G. M., \& Millar, T. J. 1992, ApJ, 399, L71

Charnley, S. B., Tielens, A. G. G. M., \& Rodgers, S. D. 1997, ApJ, 482, L203

Chiar, J. E., Pendleton, Y. J., Geballe, T. R., et al. 1998, ApJ, 507, 281
Cuppen, H. M., \& Herbst, E. 2005, MNRAS, 361, 565

Cuppen, H. M., \& Herbst, E. 2007, ApJ, 668, 294

Dartois, E., Schutte, W., Geballe, T. R., et al. 1999, A\&A, 342, L32

Duley, W. W., \& Williams, D. A. 1984, Interstellar chemistry, ed. W. W. Duley, \& D. A. Williams

Fuchs, G. W., Cuppen, H. M., Ioppolo, S., et al. 2009, A\&A, 505, 629

Garrod, R., Park, I. H., Caselli, P., et al. 2006, Faraday Disc., 133, 5

Garrod, R. T., Weaver, S. L. W., \& Herbst, E. 2008, ApJ, 682, 283

Gerakines, P. A., Schutte, W. A., \& Ehrenfreund, P. 1996, A\&A, 312, 289

Gibb, E. L., Whittet, D. C. B., Boogert, A. C. A., et al. 2004, ApJS, 151, 35 Goldsmith, P. F., \& Li, D. 2005, ApJ, 622, 938

Hasegawa, T. I., \& Herbst, E. 1993, MNRAS, 263, 589

Herbst, E., \& Millar, T. J. 2008 (London: Imperial College Press)

Herbst, E., \& van Dishoeck, E. F. 2009, ARA\&A, 47, 427

Hiraoka, K., Sato, T., Sato, S., et al. 2002, ApJ, 577, 265

Hornekær, L., Baurichter, A., Petrunin, V. V., et al. 2005, J. Chem. Phys., 122, 124701

Jørgensen, J. K., Schöier, F. L., \& van Dishoeck, E. F. 2005, A\&A, 437, 501

Katz, N., Furman, I., Biham, O., Pirronello, V., \& Vidali, G. 1999, ApJ, 522, 305

Keane, J. V. 2001, Ph.D. Thesis, Rijksuniversiteit Groningen

Kolasinski, K. W. 2002, Surface Science (West Sussex: John Wiley \& Sons Ltd) Lacy, J. H., Knacke, R., Geballe, T. R., et al. 1994, ApJ, 428, L69

Maret, S., Ceccarelli, C., Caux, E., et al. 2004, A\&A, 416, 577

Maret, S., Ceccarelli, C., Tielens, A. G. G. M., et al. 2005, A\&A, 442, 527

Öberg, K. I., Linnartz, H., Visser, R., \& van Dishoeck, E. F. 2009a, ApJ, 693, 1209

Öberg, K. I., van Dishoeck, E. F., \& Linnartz, H. 2009b, A\&A, 496, 281

Öberg, K. I., Bottinelli, S., \& van Dishoeck, E. F. 2009c, A\&A, 494, L13

Öberg, K. I., Garrod, R. T., van Dishoeck, E. F., \& Linnartz, H. 2009d, A\&A, 504,891

Pontoppidan, K. M. 2006, A\&A, 453, L47

Pontoppidan, K. M., Dartois, E., van Dishoeck, E. F., Thi, W.-F., \& d'Hendecourt, L. 2003, A\&A, 404, L17

Pontoppidan, K. M., van Dishoeck, E. F., \& Dartois, E. 2004, A\&A, 426, 925 Pontoppidan, K. M., Boogert, A. C. A., Fraser, H. J., et al. 2008, ApJ, 678, 1005 Ruffle, D. P., \& Herbst, E. 2000, MNRAS, 319, 837

Schöier, F. L., Jørgensen, J. K., van Dishoeck, E. F., et al. 2004, A\&A, 418, 185 Skinner, C. J., Tielens, A. G. G. M., Barlow, M. J., et al. 1992, ApJ, 399, L79

Stantcheva, T., Shematovich, V. I., \& Herbst, E. 2002, A\&A, 391, 1069

Thi, W.-F., van Dishoeck, E. F., Dartois, E., et al. 2006, A\&A, 449, 251

Tielens, A. G. G. M., \& Hagen, W. 1982, A\&A, 114, 245

Tielens, A. G. G. M., Tokunaga, A. T., Geballe, T. R., et al. 1991, ApJ, 381, 181 van der Tak, F. F. S., van Dishoeck, E. F., \& Caselli, P. 2000, A\&A, 361, 327 Vegard, I. 1930, Z. Physik, 61, 185

Watanabe, N., \& Kouchi, A. 2002, ApJ, 571, L173

Whittet, D. C. B., Gerakines, P. A., Hough, J. H., et al. 2001, ApJ, 547, 872 